Florida International University FIU Digital Commons

FIU Electronic Theses and Dissertations

University Graduate School

7-8-2009

\title{
Transdisciplinary teams and aging in place design : the interior designer's role
}

Liliana Alicia Custy

Florida International University

DOI: $10.25148 /$ etd.FI14061577

Follow this and additional works at: https:// digitalcommons.fiu.edu/etd

Part of the Art and Design Commons, and the Interior Architecture Commons

\section{Recommended Citation}

Custy, Liliana Alicia, "Transdisciplinary teams and aging in place design : the interior designer's role" (2009). FIU Electronic Theses and Dissertations. 2701.

https://digitalcommons.fiu.edu/etd/2701

This work is brought to you for free and open access by the University Graduate School at FIU Digital Commons. It has been accepted for inclusion in FIU Electronic Theses and Dissertations by an authorized administrator of FIU Digital Commons. For more information, please contact dcc@fiu.edu. 
FLORIDA INTERNATIONAL UNIVERSITY

Miami, Florida

TRANSDISCIPLINARY TEAMS AND AGING IN PLACE DESIGN;

THE INTERIOR DESIGNER'S ROLE

A thesis submitted in partial fulfillment of the

requirements for the degree of

MASTER OF ARTS

in

INTERIOR DESIGN

by

Liliana Alicia Custy

2009 
To: Acting Dean Brian Schriner

College of Architecture and the Arts

This thesis, written by Liliana Alicia Custy, and entitled Transdisciplinary Teams and Aging in Place Design; The Interior Designer's Role, having been approved in respect to style and intellectual content, is referred to you for judgment.

We have read this thesis and recommend that it be approved.

Philip Abbott

Shahin Vassigh

Janine King, Major Professor

Date of Defense: July 8, 2009

The thesis of Liliana Alicia Custy is approved

Acting Dean Brian Schriner College of Architecture and the Arts

Dean George Walker University Graduate School

Florida International University, 2009 


\title{
ABSTRACT OF THE THESIS \\ TRANSDISCIPLINARY TEAMS AND AGING IN PLACE DESIGN; \\ THE INTERIOR DESIGNER'S ROLE
}

by

\author{
Liliana Alicia Custy
}

Florida International University, 2009

Miami, Florida

Professor Janine King, Major Professor

This study examined factors influencing participatory research team effectiveness in aging in place (AIP) design (Stokols, et al., 2008). Although research on AIP design characterizes AIP as collaborative process, there are few studies on the factors that affect collaboration in participatory research applied to AIP. This study used a qualitative narrative strategy in a multiple case-study analysis conducted from a transdisciplinary research (TR) perspective. The case-study focused on the factors that enhanced and constrained Open_n Prototype Initiative (OPI) team effectiveness.

TR is a precise type of teamwork of integrative endeavors, focused on the science and society interface, and aimed at knowledge-based contribution to life-world problems (Wiesmann et al., 2008). This study found that TR team (TRT) effectiveness in OPI was contingent on six factors that constrained and eight others that enhanced collaboration (Stokols, et al., 2008). The conclusions provide a foundation for developing guidelines for designing, managing and evaluating successful TR (Stokols, et al., 2008) in AIP. 
I.

INTRODUCTION

Background of the Problem......................................... 1

The Purpose Statement............................................... 5

Significance of the Study ............................................ 5

II. LITERATURE REVIEW ......................................... 6

Multidisciplinary, Interdisciplinary and Transdisciplinary Research (TR).. 6

Contextual Determinants to Collaborative Success...................... 8

Goal Setting and Identification of Common Goals and Outcomes........ 8

Leadership Issues............................................. 9

Communication.................................................. 10

Organizational Issues.............................................. 11

Aging of Baby Boomers' Generation................................ 13

Aging at Home.................................................... 14

Open Building Systems and Bensonwood Homes Open-Built System..... 17

Technological Innovations........................................ 21

Open Prototype Initiative Multidisciplinary Teams.................... 24

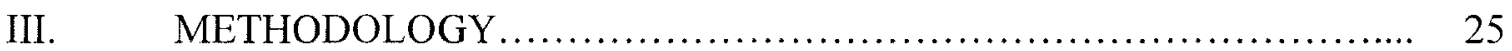

Design Procedure................................................ 25

Case Study Research Questions................................... 25

Selecting a Case Study Design................................... 27

The Researcher's Role............................................. 29

Data Collection Procedures....................................... 29

Case Studies..................................................... 29

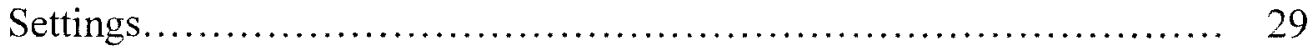

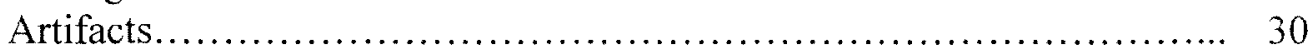

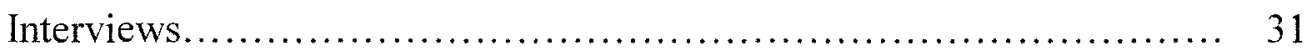

Observations..................................................... 33

Data Analysis Procedures...................................... 34

Strategies for Validating Findings................................ 35

Limitations of the Study ............................................ 37

Narrative Structure ............................................ 37

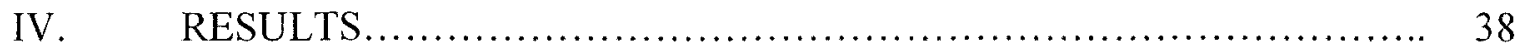

Open_n Prototype Initiative (OPI), Transdisciplinary Collaboration,

Team Performance.............................................. 38

Lack of a Designated OPI TRT Top Leader.......................... 41

Content \& Highest-Priority Setting of Common Goals and Outcomes...... 43

Lack of a Clear Pre-Defined Organizational Structure..................... 56

Cost Considerations............................................... 58

Industry Partner's Participation................................... 59 
Coalition Partners' Collaboration Readiness........................... 61

Participatory Goal Setting .......................................... 61

Communication Patterns............................................ 65

Team Members' Familiarity and Social Cohesiveness.................... 65

The Coalition Partners' Transformational Leadership Style.............. 67

Funding Issues................................................ 71

The Cost-Effectiveness Consideration in OPI TR...................... 72

The Continuity of Collaboration between Researchers and Practitioners... 74

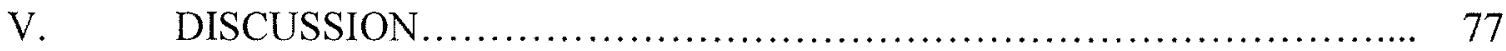

Summary of the Study ............................................... 77

Significance of the Study and Conclusions............................ 77

Recommendations.................................................. 78

LIST OF REFERENCES ............................................. 85

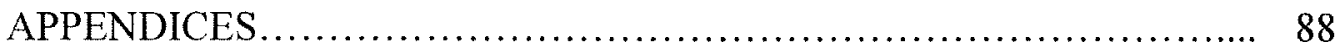




\section{CHAPTER I}

\section{INTRODUCTION}

\section{Background of the Problem}

Homes are becoming the principal center for work, learning, and entertainment, as well as energy conservation and proactive healthcare (Larson, 2002). Today, aging populations readily choose to live in high performance homes, built with quality controlled construction and efficient design (Larson, 2002). Studies show a strong trend in homeowners of the baby boom generation who prefer to remain in their homes as they age. This population, born between 1946 and 1964, is the largest in the last 100 years. This fact, in conjunction with improved medical technologies that facilitate increased life expectancies fuels predictions that this aged generation will form a large percentage of the overall population for the next twenty years.

University researchers, along with industrial leaders, are developing new models for housing that address the needs of AIP populations (Hart, 2004). These new places of living are designed to be comfortable, responsive, adaptable, high quality, healthy, energy-efficient, sustainable, cost effective, affordable, durable, and highly personalized (Hart, 2004). Innovations in housing systems connected with AIP seek to integrate developing technologies in housing through the incorporation of ubiquitous, persuasive computing (Essa, 2000), electronically-enhanced assistive technologies, and telecare (Barlow, et al., 1997). In essence, tools designed to facilitate communication, lifelong learning and increase residents' ability to continue living independently (Center for Aging Services Technologies, CAST, 2008). Even though the nature of the research in AIP is complex, individual scientific disciplines and societal bases are exploring different 
solutions. Most research has taken a thematic approach to the house of the future, using designations like: a) smart house; b) intelligent house; c) aware house; e) green house; and f) networked house (Venkatesh, 2001). Most leading international projects conduct research on modern sensor-embedded houses or smart homes, and associated technologies of wearable/implantable monitoring systems and assistive robotics, often designed as components of a larger smart home environment (Chan, Esteve, Escriba, \& Campo, 2008).

Contrary to the prevailing single discipline approach, the Massachusetts Institute of Technology (MIT) has developed a holistic multidisciplinary approach to AIP design, addressing the complexity and diversity of problems associated with updating the housing industries for AIP populations. This multidisciplinary effort is called the Open $n$ Prototype Initiative (OPI), a part of the Open Source Building Alliance (MIT, 2008). By employing cross participation among the scientific, professional, practitioner, community and building industry sectors, OPI's objective is to develop a series of four prototype houses to serve as a blueprint for future homes. OPI is based on Architect Habraken's theory of "Open Building" (OB). The two principal aspects of $\mathrm{OB}$ are 1) a disentangled and layered approach to design and construction, with each layer defined by its life span and anticipated need for future alteration; and 2) design by multidisciplinary teams that get involved early in the process.

In multidisciplinary research, participants remain theoretically and methodologically attached to their own disciplines, while with inter or transdisciplinary research, participants seek to integrate the analytical strengths of two or more disciplines (Stokols, et al., 2008). Although OPI is not a project originally formulated in terms of 
transdisciplinary collaboration, the OPI falls in the realm of TR, and can be described as a more conducive approach to successful collaborative research efforts, addressing contemporary complex societal issues (Stokols, et al., 2008). OPI addresses real life problems such as housing, aging populations, health, technology, and sustainability. Thus, this study examined OPI success in attaining goals through the lens of TR factors' facilitation or constraint of participants' effectiveness, rather than through a multidisciplinary lens. The goal of the research was to provide observations that could be instrumental in guiding future projects. From this perspective, a qualitative analysis of the varied stakeholder points of view on issues related to OPI and TR processes provides an original approach to evaluating TR effectiveness in reaching OPI's goals, and outcomes.

Transdisciplinary or team science is a unique form of intellectual teamwork (Stokols, et al., 2008) It refers to a relatively new form of coordinated and integrationoriented research that focuses on the promotion of interdisciplinary collaboration between researchers of different disciplines (Stokols, et al., 2008). TR centers on improving science-based contributions intended to solve complex problems in real life (Stokols, et al., 2008), and AIP research is a good example of this type of research. TR requires alert collaboration between science and society, as well as careful consideration of diversity of goals, values, expectations, related power and social representation (Wiesmann, et al., 2008). Collaborations and negotiations among stakeholders and/or disciplines are built on approaches of mutual learning and having goal oriented participation as an entry point (Wiesmann, et al., 2008). Researchers have examined transdisciplinary research teams (TRT) working in diverse areas of applied research, identifying factors that facilitate or constrain teams' effectiveness (Stokols, et al., 2008). 
AIP design is an area of the interior design profession that is increasing in importance, given that AIP populations are rapidly becoming one of interior designers' most demanding clientele (ASID, 2004). An article published in the March-April 2009 issue of "Icon," the bi-monthly publication of the Association of Interior Designers (ASID), suggests that interior designers should understand the point of view and project process of other team members such as architects, contractors, builders and developers (Rebholz, 2009). Although the article suggests that the success of interior designers is directly related to the professional's ability to work collaborative in teams, the author only mentions professions that are traditionally related to the interior design profession, it fails to recognize that interior design professionals working on AIP will also be working with teams composed of professionals from a wide range of disciplines, e.g., healthcare, computing technology, social workers, family members, and others. Although review of literature indicates that this profession could contribute to multidisciplinary teams working on topics associated with AIP design, there is a scarcity of information regarding interior designers' involvement in research and/or working in teams representing diverse disciplines and layers of society. There are underlying reasons for the apparent lack of integration of valuable resources that interior design professionals could offer.

Multidisciplinary teams, based in research universities, may not be aware of the specific scientific content involved in the interior design's body of knowledge. On the other hand, multidisciplinary research teams may have tried to involve interior designers in the process, and for some reason were not confident that interior designer's contributions would be productive. Thus, this study also explored whether factors 
associated with TR are connected or not with the absence or the participation of interior designers in OPI' multidisciplinary teams

\section{The Purpose Statement}

The purpose of this qualitative study is to conduct a multiple case study involving Open_1 and Open_2 prototypes. The objective is to identify variables and contextual influences affecting the effectiveness of transdisciplinary collaborations which resulted in the OPI's first two built prototypes. This study will focus on the factors that facilitated or constrained collaborative effectiveness in achieving OPI's objectives.

\section{Significance of the Study}

An understanding of the factors that enhance or constrain TR effectiveness will allow researchers to make educated decisions, to avoid persistent stumbling blocks and/or potential conflicts that affect this type of work, and to develop helpful guidelines for designing, managing, and evaluating successful TR in AIP (Wiesmann, et al., 2008). This study will be of interest to researchers, professionals, practitioners, and educators in diverse disciplines, as well as to stakeholders in general, who are actually involved in projects of this nature or who plan to get involved in the future. 


\section{LITERATURE REVIEW}

\section{Multidisciplinary, Interdisciplinary and Transdisciplinary Research}

The main consideration for this proposal is that OPI is a complex project involving multiple stakeholders representing diverse disciplines and numerous organizations who have joined forces with the objective of developing a series of prototypes. Participants consider this process as an opportunity for mutual learning, as the end result is valued as much as the course of action taken for the integration of various perspectives, multiple disciplines, and diverse knowledge. Lessons learned with the development of one prototype will be used to improve the following prototypes with the intent of designing a blueprint for AIP developments.

One of the principal characteristics of TR refers to the way research addresses collaborations and negotiations among various disciplines and stakeholders, ideally starting with a problem definition and continuing throughout the entire research process (Wiesmann, et al., 2008). As part OPI's contributions to solving specific problems in "life-world," OPI intends to redefine the precise nature of problems to be addressed and solved, considering that problems and solutions are not predetermined, but are defined cooperatively by actors from science and the "life-world" (Wiesmann et al, 2008). "Lifeworld" is a core term of TR and refers to the human world prior to scientific experience and is used by TR to describe the structural properties of social reality, as well as to mark the differences between the scientific communities and other communities, such as the private sector, public agencies, and civil society (Pohl \& Hirsch Hadorn, 2007). Several authors affirm that TR is a unique form of intellectual teamwork and a major avenue for 
enhancing science based on life-world, as it has the potential to stimulate innovation across a wide array of disciplines (Wiesmann, et al., 2008).

This study bases its main proposal on the conceptual differences between multi, inter, and transdisciplinary research. OPI has characteristics that are essential to effective transdisciplinary collaboration. Among them is the development of shared conceptual frameworks that integrate and transcend different disciplinary perspectives represented among team members, and reflect higher degrees of integration than those achieved through interdisciplinary collaboration (Rosenfield, as cited by Stokols, et al., 2008). In reference to multidisciplinary research, several authors consider that it is the leastintegrative form of cross-disciplinary interaction, each discipline works in a selfcontained mode with minor cross fertilization between disciplines, or synergy of outcomes (Pohl \& Hirsch Hadorn, 2007). In multidisciplinary teams, participating scholars remain conceptually and methodologically anchored in their respective fields and there is no integration of knowledge, while interdisciplinary research incorporates and coordinates the critical strengths of two or more often dissimilar disciplines to create a new hybrid discipline (Rosenfield, as cited by Stokols, et al., 2008).

OPI fits the definition of a TR collaboration because although participants remain grounded in their own disciplines, they search to integrate different approaches and develop new knowledge through the analyses of complex empirical questions (systems knowledge), determine goals for better analysis of problems (target knowledge), and investigate how existing practices can be changed (transformation knowledge) (Wiesmann, et al., 2008). TR addresses the "uncertainties in knowledge" (Pohl, et al., 2008), the empirical diversity and complexity, and debates about which parameters are 
relevant, how they are connected in concrete processes, and what disciplines need to be involved (Pohl, et al., 2008). In TR terms, OPI is a "sustainable development," as it attempts to develop a new global socio-political model for updating practices in the housing industries in connection with AIP populations, and achieve more equitable opportunities within and between generations. In addition, the OPI model has to take into account the constraints imposed by technology, as well as the ability of social organizations and the environment to meet present and future needs (Pohl, et al., 2008).

OPI is a labor-intensive form of collaborative research, as defined by TR. Diverse scholars suggests that investments in TR are not uniformly cost effective (Stokols, et al., 2008). To make the most of shared efforts, especially in view of worldwide economic recessions, stakeholders should thoroughly reflect on the unique risks and additional criteria of contextual determinants to collaborative success intrinsic to TR initiatives.

\section{Contextual Determinants to Collaborative Success.}

\section{Goal Setting and Identification of Common Goals and Outcomes}

TR researchers suggest that participatory goal setting is a very important consideration, given that one of the principal challenges for the design and management of TR is to tailor research projects to the unique and highest-priority goals of each stakeholder group (e.g., researchers, funding agencies, community members, organizations, and elected officials) (Stokols, et al., 2008). Goals may change over time and be phase-specific (Stokols, et al., 2008). Different stakeholders may assign different priorities to project-specific goals, and as such, these priorities should be clearly specified at the outset of each initiative by major stakeholder groups (Stokols, et al., 2008). 
TR common goals and outcomes must be clearly identified. Citizen groups, practitioners, and researchers bring to their partnerships diverse and often competing interests, problem-solving agendas, differences in ethical practices and beliefs, and different timelines to achieve the coalition's goals (Stokols, et al., 2008). Conflicts may undermine the team's performance when groups directly or indirectly involved have a variety of interests, often incompatible (Pohl, et al., 2008). Studies suggest that effective teams perceive objectives as attainable and share clear, identifiable goals and researchprinciples (Stokols, et al., 2008). Recent studies highlight the importance of the continuity of collaboration between researchers and practitioners over extended periods and across the various phases of action-research, including the formulation of goals and the translation of research into academic and scientific publication, as well as community empowerment (Stokols, et al., 2008).

\section{Leadership Issues}

Most studies agree that leadership style is a fundamental consideration in team effectiveness. Several authors suggest that in TR, transformational styles of leadership produce more potent teams and achieve higher levels of performance. A transformational leader offers team members a strong vision of collective success; bring out the best in each member and empower each member to personally and collectively reach important goals (Stokols, et al., 2008). Leaders who are supportive, democratic, empowering, and committed and who encourage cooperation and engage the support of others significantly enhance transdisciplinary collaborations within research settings (Stokols, et al., 2008). 
Studies suggest that members should be skilled in group processes, team development, negotiation, conflict resolution, and interpersonal communication, in addition to their skills in research design and methods (Stokols, et al., 2008). Among members' most valued characteristics is the readiness for collaboration, particularly for its direct influence in the outcomes of community coalitions. Good communication between actors is essential to avoid disputes that arise in the "life-world" regarding whether and how certain actors need to be involved and/or their practices need to be changed (Stokols, et al., 2008).

\section{Communication}

Communication has been a topic of long-standing interest in research on group dynamics. The lack of adequate feedback and communication is a major impediment to effective team performance. Stokols, et al. (2008) affirm that regular and unconstrained communication has to be exercised regularly among team members to provide clarity about coalition goals and about member roles, and is recommended as a way to resolve disagreements or conflicts, establishing and maintaining trust among members (Stokols, et al., 2008). Research recommends that well-developed electronic communication systems should be provided to facilitate coordination among partners (Stokols, et al., 2008).

Researchers in TR conclude that essential traits of good communication patterns are prerequisites for successful remote collaboration. They emphasize the benefits of explicitly expressing enthusiasm and optimism for effective and sustained communication (Stokols, et al., 2008). Studies advise early face-to-face contact, even in 
remote collaborations and between virtual teams, to facilitate the early establishment of trust in collaboration, and to allow members the exchange of messages for clarification and feedback (Stokols, et al., 2008). Additional factors that influence effectiveness of team performance and transdisciplinary collaboration include team members' familiarity, social cohesiveness and team size (Stokols, et al., 2008)

\section{Organizational Issues}

Critical factors for effective TR collaborations refer to team organization and structure, and to the geographic scope of transdisciplinary collaboration. Teams that collaborate from sites which are located at geographically dispersed areas (e.g., for multisite initiatives), need to define a clear organizational structure. In these cases, leadership responsibilities must often be shared and coordinated among multiple directors (e.g., those having primary responsibility for scientific, financial, and administrative leadership) (Stokols, et al., 2008). Studies show that a challenge faced by community coalitions is the decline of organizational support, participation or involvement by members due to circumstances such as lack of time, insufficient resources, unsatisfactory appreciation or recognition, opposing institutional demands, loss of independence in decision making, disappointment due to lack of progress, and interpersonal differences and arguments (Stokols, et al., 2008).

Sustaining community coalitions requires providing members with adequate incentives to remain involved (Stokols, et al., 2008). These motivations include financial compensation, training and educational opportunities, peer recognition for scientific and academic members, as well as rewards for community-based research (e.g., the 
publication of findings in respected journals) (Stokols, et al., 2008). These incentives may increase the collaboration readiness of researchers and practitioners alike. Studies suggest that to facilitate coalition members to build sustainable partnerships, it is necessary to assure long-term funding by public agencies and private foundations (Stokols, et al., 2008).

Studies further suggest that the distribution of power and control is a significant consideration for the effectiveness of TR. Any perceived status differences among members, including inequitable distribution of resources, information, time, funding, decision-making power, participation, and control over aspects of the community problem-solving process, are obstacles to the achievement of coalition's goals and a major impediment to coalition progress and sustainability (Stokols, et al., 2008). Task and outcome interdependence are another important consideration in TR, requiring a balance between interdependent task and reward structures on the one hand, and opportunities for autonomous or semi-autonomous teamwork on the other (Stokols, et al., 2008).

Diverse participating disciplines, such as contributing "actors" or team partners from the natural, technical, social sciences, humanities, and industry, determine during the research process which bodies of knowledge have to be taken into account and incorporated. These decisions are aimed at producing and integrating systems knowledge, target knowledge and transformational knowledge to the TR and cannot be accurately pre-defined (Wiesmann, et al., 2008). In this regard, this study illustrates that interior designers' body of knowledge could be of great help to AIP research; even though interior designers' participation in OPI has been minimum. 
The National Council for Interior Design Qualification (NCIDQ) describes interior design as a multi-faceted profession in which creative and technical solutions are applied within a structure to achieve a built environment that is functional and attractive, enhancing the quality of life, culture, and health of occupants. The World Health Organization (WHO) defines health as "a state or infirmity" of complete physical, mental, and social well-being and not merely the absence of disease (WHO, 1948). Interior designer's profession is directly related to WHO's definition of health as it addresses topics such as indoor air quality, health in the workspace, healthcare design, lighting to improve health, accessibility, and universal design (Martin \& Guerin, 2006).

People's welfare is protected by interior designers' knowledge of elements that create well-being for people in their spaces; comfort, security, privacy, satisfaction, and stimulation are all components of welfare that are designed into the people's environments. "The Interior Design Profession's Body of Knowledge" includes six categories and 96 knowledge areas (Martin \& Guerin, 2005), all of which could be of great assistance to the OPI's multidisciplinary research teams. Knowledge areas include: communication, code and regulation compliance, design, products and materials, interior construction, and professional practice. (For Table of relationships between interior designers' body of knowledge and the OPI, see Appendix).

\section{Aging of baby boomers' generation}

Studies regarding the future of the aging community indicate that the size of the baby boomer population will have a significant impact on the elder care and on the housing industries. The baby boomer generation is comprised by seventy-six million 
babies that were born in North America from 1946 to the end of 1964; those surviving in 2030 will be between the ages of 66 and 84 years old (American Association of Retired Persons, AARP, 2004; Hart, 2004). The U.S. Department of Health and Human Services (DHHS) projects that by 2015 and for the first time in U.S. history, people age 65 and over will outnumber children under age 5 (2007). By 2030, one in every 8 of the earth' inhabitants will be 65 and older (DHHS, 2007). By 2010, the 85+ population in the U.S. is projected to increase $40 \%$ (DHHS, 2007). Some researchers predict that death rates at older ages will decline more rapidly than is reflected in the U.S. Census Bureau's projections, which could lead to the increased growth of this population (DHHS, 2007).

\section{Aging at Home}

A strong trend shows that homeowners prefer to remain in their homes as they age (AARP, 2008). AIP design addresses satisfying the housing needs of people as they age, taking into consideration that all people age differently, and that each person, with or without disabilities, has individual needs. Statistics show that reported disabilities increase with age, and with the elderly population growing, the disability rate and the number of older adults needing assistance with activities of daily living will increase, creating more demand for care options (DHHS, 2007). Thus, housing design for AIP must afford people with disabilities the opportunity to stay at home. Physiological changes associated with aging, such as changes in vision, changes in hearing, changes in strength affecting reach, mobility and agility, changes in color perception, changes in memory and changes in sense of orientation, are additional considerations for design that supports AIP (ASID, 2007). An important issue becomes considering AIP when 
designing for clients who may not yet be considered aged. In designing for an AIP population, designers should attend to the client's short-term aspirations as well as to their long term needs (ASID, 2007).

Interior designers associate universal, barrier-free, accessible design features with designing for the AIP populations. The Center for Universal Design at North Carolina State University defines universal design as "designing for all people of all ages and abilities" (1998), and is an important tool for AIP design (ASID, 2007). The concept of universal design addresses specific physical disabilities, as well as a wide array of physical, cognitive, and linguistic abilities of people (Adaptive Environments, 2001), and exceeds what is mandated by ADA. Universal design is not only about accommodating a wide range of users, but also about accommodating the same user over time (ASID, 2007).

Worldwide, improved medical technologies allow more critically and seriously ill people to survive. This fact, along with a growing elderly population, has raised the visibility of the issues of accessibility and greater usability (North Carolina State University, 1997). In this sense, good design is equivalent to custom design or designing for the user's specific needs. Baby boomer populations want to preserve their independence; by adopting universal design principles and solutions, residents can age with dignity and respect in their own homes (ASID, 2007). The mature market wants modifications to their homes to increase safety, efficiency, comfort, convenience, ease of access and mobility (AARP, 2004; ASID, 2007).

Although TR in AIP is of growing importance, many scholars have yet to incorporate the concept in their specific teaching or practices. Harvard professor Cynthia Leibrock, 
for example, teaches courses related to "Design research on aging" and "Innovative design strategies for health care." Leibrock's web site provides online continuing education on topics of AIP and universal design. However, there is no reference in Leibrock's web site connecting successful AIP research and technological advances in AIP design with multidisciplinary teams. In addition, the ASID web site and publications do not address these topics.

A number of organizations dedicate efforts to educate the public about AIP, including major organizations such as the American Institute of Architects (AIA), American Society of Interior Designers (ASID), National Aging in Place Council, National Council on Aging, U.S. Department of Housing and Urban Development, as well as many others. AARP has publications as well as web site information connecting AIP design to the application of universal design principles. This is an important educational message to the community, reinforcing the concept that AIP design should be based on the ADA recommendations as a guideline, and embrace universal design principles as a mandate. However, none of these organizations have connected AIP to TR.

Work associating multidisciplinary teams with technological and scientific research on topics related to AIP design is mainly conducted by universities and published by scholarly reviewed journals, such as BT Technology Journal, Adaptive Environments, IEEE Personal Communications, ACM, Cambridge Institute of Technology, Massachusetts Institute of Technology, and the Georgia Institute of Technology. Besides universities, one national organization, "The Center for Aging Services Technology" (CAST), has posted an interesting educational video on its web 
site, entitled "Imagine-The future of aging: vision video introductory guide," which provides information on technological advances for AIP populations.

Interior designers, together with other professionals interested in AIP, should be trained in TR principles, and integrate practices that facilitate team effectiveness. Given interior designers' professional education, training and expertise, AIP transdisciplinary teams should take advantage of the unique insights and perspectives of interior design's body of knowledge. With a balanced TR approach, one that incorporates the strengths of all relevant disciplines, the future demands of AIP design can be effectively and successfully met.

\section{Open Building Systems and Bensonwood Homes Open-Built system}

Studies show that construction systems are one of the principal challenges of fully integrating the computing infrastructure and service delivery aspects of new technologies designed for AIP (Chan, et al., 2008). A main concern of researchers who study technologies for AIP is how to design a built environment that can be stable and provide support, and at the same time, be adaptable and afford change (Kendall, 2006). Literature review suggests that the use of open building systems, as developed by architect John Habraken, former chair of the MIT Department of Architecture, allows the integration of new and developing technologies to buildings (Larson, 2002). Among Habraken's main ideas is that designing is a process with multiple participants, including different kinds of professionals, and emphasizes that users and/or inhabitants may make design decisions as well as professionals (Habraken, 1976). 
OB thinking takes a layered approach to building, with each layer defined by its life span and anticipated need for future alteration. The building is viewed as a wellorganized combination of systems and sub-systems which are disentangled from each other, increasing the opportunities for better organization, increased consistency, quality, greater control and flexibility (Habraken, 1994). Major systems include: building site, division of space inside the building, wiring, cabinets, and other items people put in the building structural envelope, such as plumbing, heating/cooling, and furniture (MIT, 2008). According to this theory, every new house would have a structural frame, or "chassis", that would be expected to last 200 years or more. The chassis is the fixed, long-term infrastructure of the building and includes structure, raceways, plumbing and electrical risers, etc. (Larson, 2002). The chassis would be fitted with an integrated "interior infill" with cabinetry-like interior components, containing modular devices, sensing lighting and control systems that are configured by the occupant. As occupants' requirements change and new solutions evolve, the configured interior elements can be rearranged, upgraded or replaced with minimal disruption to the home, in a very easy, clean and cost-effective way (Larson, 2002). One of the main problems to home masscustomization is the lack of standardization of housing materials; the construction industry needs to provide customers with standardized systems of walls, floors, roofs, etc.; with standards analogous to the USB ports standard for computers (Benson, 2007). The development of a process of standardization is critical to the production of affordable mass-customized homes.

Based on Habraken's theory of Open Building, Tedd Benson, founder and owner of Bensowood Homes (BH), has developed a design and construction system called $\mathrm{BH}$ 
"Open-Built system." The ultimate purpose of advancing the housing industries through BH Open-Built systems is to provide design solutions to accommodate different clients changing needs in an easy, cost effective, healthy and sustainable way. As in Habraken's theory, BH's design and construction process is based on multidisciplinary teams working together on home projects; these projects are studied by designers, architects, engineers, building systems teams, subcontractors and other stakeholders and discussed with the owners, who are considered an important part of the design team. The following is a list of the principles behind BH's Open-Built System (MIT, 2008):

a) Design for Flexibility

b) In house design team: homes are designed and assembled from pre-designed components, which can be an item as large as a roof or as small as a cabinet door.

c) Components are designed and engineered, assuring quality, variety, cost and fit

d) Mass-customization: a component library with a collection of pre-designed parts of a home enable customization of designs

e) The goal is to provide the client with a "custom home" at a standard price

f) Multidisciplinary in-house meetings at every stage of the project, involving the major stakeholders and key subcontractors in the planning process for each project, minimizing conflicts that are typical in a construction site

g) Prefabrication of components; conflicts about time, space, and quality are minimized

h) Homes must be unique and adaptable 
i) Precise Positioning: a well-defined and precise 3D measurement and positioning system, used by designers and manufacturers, allows for efficient decision making and less waste.

j) Build it twice (CAD 3D virtual construction). Planning inclusively and building virtually

k) Disentanglement of systems: $\mathrm{OB}$ views the home as a collection of layered systems

1) Keeping these layers separate and disentangled allows for the creation of systems that are appropriate for their extended life spans.

m) Access to systems, commensurate with the needs for future modification is designed into the initial plan (MIT, 2008)

n) The layers include: the site, the structure, the skin, the space plan, the services (wiring, plumbing, HVAC, etc) and the elements within the home (furniture, occupants, etc)

1. Delivering Pre-built Systems to the Site (MIT, 2008)

Compared to other systems of construction, Open-built systems offer the following advantages:

1. Controlled working condition in the shop; weather conditions do not affect the work schedule

2. Assurance of quality of materials and workmanship

3. Computerized numerically-controlled machinery can be incorporated

4. Jigs and fixtures can be installed in the shop 
5. Brief construction time-on-site, minimizing disturbances, such as noise and dust, to people in the area.

6. Open-Built systems can retrofit existing homes.

$\mathrm{BH}$ has recently decided to include an interior designer to their in-house OpenBuilt multidisciplinary team. Interior designers' areas of expertise are related to many areas of the Open building systems; from concept development and design, to drawing, construction documents, and management. Interior designers use an integral and rounded approach to designing interiors, based on tailoring solutions to clients. Studies show that Open-buildings' infill is designed as cabinetry systems; cabinetry and millwork are essential to interior designers' knowledge. BH's decision raises one of the questions under investigation. What did BH's teams or design outcomes lack, that they thought that interior designers could contribute? How did BH determine that interior designer's body of knowledge should be taken into account and incorporated into their multidisciplinary team? AIP design, given the structure of OPI TRT, should incorporate all disciplines related to home design. The OPI TRT concept and practice must incorporate interior design's body of knowledge to fully capitalize on the potential of TR, both for the success of the model and future projects.

\section{$\underline{\text { Technological Innovations }}$}

The Open Source Building Alliance is a major initiative of "House_n Research Group" led by Kent Larson and researchers at MIT Department of Architecture, in partnership with Tedd Benson, founder of Bensonwood Homes, and in association with 
other industrial leaders. The Open Source Building Alliance has the goal to develop, through multidisciplinary research, a new model for creating more responsive, adaptable, higher quality, and cost-effective homes. OPI is an initiative of the Open Source Building Alliance which has the goal of developing a series of prototypical homes that test a new model for the design and fabrication of highly responsive places of living (MIT, 2008).

The review of literature regarding technological innovations associated with smart homes of the future also indicate that the implementation of these technologies within the interior of the home will impact and be impacted by the interior design of the building. Smart homes of the future are an integrated system of electronics, sensing equipment, and other home technologies that communicate with one another and a central controlling computer. The system is designed to know or sense things about the occupant and the environment and will be able to "make adjustments and offer reminders without human intervention" (Knetch, 2004). Specifically, the AIP technology would have the capacity to sense and identify potential crises, and then automatically contact services as needed: augment a senior adult's memory; and track behavioral trends by creating social connections between senior adults and their relatives (Sanders, 2000).

In terms of intervention, basic sensing technology could help relatives determine when an incident has occurred or prevent it from occurring. Process innovation relates to the introduction of ubiquitous and persuasive computing and telecare (Barlow, et al., 1997). Eventually, ubiquitous technology in the home might be less costly than the cost to live in assisted care or nursing home facilities. Thus benefits of the incorporation of emerging technologies in AIP design are both social and financial (Sanders, 2000). 
Technology companies are developing products and services for home-based health care, work, commerce, play, energy, conservation, and communication (Hart, 2004).

Researchers at MIT believe that AIP research has to develop design components that provide adaptability to a home setting, making the home responsive to occupants' changing needs. MIT is developing pervasive computing systems to be integrated into the home, as a technological support to monitor changes in residents' behavior and/or the home environment. MIT interdisciplinary researchers believe that there is no single 'home of the future'. MIT teams aim to develop technologies and design strategies with flexible environments to meet occupants' physical and cognitive needs. Their main consideration is that technology should not be used primarily to automatically control the environment but instead to motivate occupants learning and behavior change in the home (Intille, 2002)

As increasing number of older adults choose to age in place, adapting homes to accommodate recent and developing technological developments designed to assist and support older adults' activities of daily living will come under the domain of interior design professionals. ASID describes this part of the population as a central part of the interior designers' future client base. To better serve this important number of potential clients, interior designers need to incorporate technological advances into their knowledge base in order to propose solutions to integrate innovations to the projects for the home. 


\section{Open Prototype Initiative Multidisciplinary Teams}

Although multidisciplinary research is at the base of the OPI research project, literature review offers scarce information on topics regarding OPI TRT organizational structure and members' characteristics. Although literature review describes OPI's goals in detail, there is scarce information regarding coalition stakeholder organizations' characteristics. For example, there is no insight regarding whether coalition partners share the same goals and agendas, whether they identify identical highest-priority ranking of goals, whether they have equal expectations for outcomes, whether they have similar leadership styles, whether they share analogous problem solving methods and decision making strategies. OPI's developments are directly influenced by stakeholder partners' inner organization characteristics. TRT members may not be aware of the importance of considering the above mentioned contextual factors affecting effective TR team work. This study seeks to analyze these considerations, and evaluate OPI team work through the lens of TR's principles and TRT's effectiveness. 


\section{METHODOLOGY}

\section{Design Procedure}

\section{Case Study Research Questions}

The methods section of this study is organized in the following sections: design procedure, data collection procedures, data analysis procedures, results and discussion. The qualitative narrative strategy was based on the analysis of a multiple case study. This study focused on factors that facilitated or constrained OPI teams' effectiveness from a TR point of view, considering that the participants represented different sciences, diverse disciplines, various organizations and different layers of society. The conclusions drawn from this study will be helpful as a foundation for developing helpful guidelines for designing, managing and evaluating successful TR (Stokols, et al., 2008) in AIP.

The research question explored was 1) which were the factors that facilitated or constrained teams' effectiveness (Stokols, et al., 2008) in achieving OPI's goals in O1 and $\mathrm{O} 2$ ? The hypothesis behind this research question was that team-science initiatives may have underestimated the need to better understand how contextual aspects influence the effectiveness of transdisciplinary scientific collaboration (Stokols, et al., 2008). This study explored the complexity and multiplicity of collaborative decisions that had to occur in order to implement OPI's goals effectively (Yin, 1989). Events and decisions (factors) that affected the overall pattern of complexity were identified in a causal sense to explain OPI team's effectiveness (Yin, 1989).

'Factors' were utilized as variables in this investigative process, which consisted of analyzing, contrasting, comparing, replicating, cataloguing and classifying (Creswell, 2002) the data collected from open-ended interviews and from on-site observations. The 
interviews conducted with OPI's principal stakeholders were recorded and later transcribed verbatim; notes were taken from on-site observations. A Likert-Type scale was designed as an instrument to organize and evaluate data. The multiple case-study research took place in $\mathrm{O} 1$ and $\mathrm{O} 2$ natural settings; an observational approach enabled the researcher to develop a level of detail about the settings, to be highly involved in actual experiences of the stakeholders and teams' participants (Creswell, 2003), and to focus on understanding the dynamics present within the settings (Yin, 1989).

The literature review on research related to the technological advancement of residential environments and related industries in connection with aging in place, indicated that most of the research has adopted thematic focuses, revealed by designations like: a) GatorTech Smart House; b) Intelligent House; (Honeywell); c) Georgia Tech Aware Home; d) Green House (Honeywell); e) Networked House (University of Sao Paulo, Brazil); f) Adaptive House (Boulder, Colorado); g) Microsoft Easy Living Project; h) Aging in Place (University of Missouri-Colombia); i) Elite Care (Portland Oregon); j) The MavHome Project (University of Texas, Arlington); k) Welfare Techno-Houses (Japan); 1) The Ubiquitous Home (Japan); m) The Context-Awareness Project (Japan); n) The Matsuoka Smart House (Osaka, Japan); o) The Smart House (New Zealand); etc.; (Chan, et al, 2008), (Venkatesh, 2001). In USA, Canada, Japan, Korea, United Kingdom, Holland, Norway, France, Spain, Australia, New Zealand, in almost every continent, and both based in universities and the industry, researchers are developing similar prototypes and technologies (Chan, et al., 2008).

Literature review indicate that a shared characteristic of the above mentioned projects is that researchers are developing environmental friendly prototypes, systems, 
and devices to create assistive environments and programmable pervasive spaces. Homes will sense themselves, and their residents, to enact mapping between the physical world, and remote monitoring and intervention services (Chan, et al., 2008). The main challenges of successful prototypes that use "smart homes" technologies reside on; 1) a full integration of these technologies into the construction of homes; 2) a comprehensive, respectful understanding of intended users' habits and requirements where proposed technological solutions should match or exceed residents' needs and standards of living; and 3) a research into legal and ethical problems, both in relation to users and providers, in connection with privacy issues, requirements, and satisfaction (Chan et al., 2008).

OPI research project presented a horizontal or global approach to the house of the future (Alves, 2004). OPI offered solutions to two of the smart homes' challenges (Chan et al., 2008). Open-Built system allowed the house to be easily updated, and TRT suggested solutions from multiple perspectives, diverse disciplines, and across societal fields, thus matching or exceeding clients' expectations. Regarding the third challenge, MIT ubiquitous computing system's application was confronted with OPI TRT legal and ethical considerations. In addition, OPI will develop a series of four different prototypes overtime; this extended period of time will enhance TR teamwork, support good communication and trust, as well as the development of shared knowledge among team members.

\section{Selecting a Case Study Design}

This study employed a multiple-case study design, and analyzed O1 Crotched Mountain Rehabilitation Center, in Greenfield, New Hampshire and O2 Unity House, 
Campus of Unity College, in Unity, Maine. Even though the major reasons for conducting a single-case study existed, a multiple-case study was conducted. The main motivation for conducting a multiple-case study was to compare the two prototypes, and to extract conclusions from the comparison. O1, located in Greenfield, N.H., preceded $\mathrm{O} 2$, located in Unity, Maine. To verify replication, this study considered the sequence between $\mathrm{O} 1$ and O2; lessons learned in O1 were applied in O2 (Yin, 1989). Even though the two prototypes share main basic features, they had some major differences; the two prototypes were designed for special purposes and addressed specific clients' needs.

The study explores $\mathrm{O} 1$ and $\mathrm{O} 2$ settings, and examines the complex dynamics that intersected or crossed into one another. Stakeholders' semi-structured, open-ended interviews, as well as on-site observations, were conducted in $\mathrm{O} 1$ and $\mathrm{O} 2$ and in $\mathrm{BH}$ ' facility. The multiple-case study was of the "embedded" class, involving more than one unit of analysis, meaning that within the two case studies, attention was given to subunits (Yin, 1989). The factors facilitating or constraining OPI collaborative team effectiveness in connection with achieving OPI's goals were the units of analysis explored in $\mathrm{O} 1$ and $\mathrm{O} 2$ case studies. This study identified Stokols et al.'s factors (2008) as units of analysis, and the OPI's goals as subunits of analysis. (For OPI's goals and design elements, see appendix, tables 3 thru 9). Thus, a comprehensive study of the factors affecting teams' effectiveness was conducted in connection with the success in attaining OPI's goals (Yin, 1989).

On-site observations data was used for replicating information collected from the semi-structured, open-ended interviews conducted with OPI's principal stakeholders. 
Artifacts were observed and analyzed. Relevant data related to the artifacts was recorded on field notes.

\section{The researcher's role}

I believe in the benefits of working in multidisciplinary teamwork. In my thirty years experience working as project architect, project manager, general contractor, designer of interiors and job site manager, I have successfully partnered with multidisciplinary teams. This work experience gives me first hand knowledge of what I have addressed in this study.

I am a baby boomer, and as such I am very interested in aging in place (AIP) design. As an architect and general contractor working on interiors, I am very interested in updating the housing industry. The OPI is designed as a holistic transdisciplinary research project that would benefit the baby boomer population that has made the decision to age at home. OPI will also provide comprehensive and environmentally friendly solutions to modernize the building industry.

\section{Data Collection Procedures}

\section{Case Studies}

\section{Settings}

a) MIT Open Prototype Initiative, House_n Research Group, Department of Architecture Massachusetts Institute of Technology 
The OPI is a collaboration between the Massachusetts Institute of technology (MIT) House n Research Consortium, Bensonwood Homes (BH) and other industry partners and sponsors. The objective is to develop a series of four prototype homes, deploying advanced designs, materials, systems, and fabrication strategies, to test a new model for the design and fabrication of highly responsive places of living. OPI plans to build each home in 20 working days, every 18 months throughout 2010 (MIT, 2008).

\section{Artifacts}

The two artifacts were $\mathrm{O} 1$ and $\mathrm{O} 2$.

\section{a) O1 Crotched Mountain Rehabilitation Center, Greenfield, New Hampshire (CM)}

O1 was the first prototype built. It is a three-story 28 by 46 foot house, sited on the main campus of CM. CM Rehabilitation Center is a non-profit hospital, a rehabilitation facility, and school for children and adults with disabilities. It serves patients in New Hampshire and New York State. This building serves as a transitional home for brain surgery patients leaving the Brain Injury Center.

\section{b) O2 Unity House, at Unity College, Unity, Maine}

$\mathrm{O} 2$ was the second prototype built. It is the house for the president of Unity College, Maine. It is divided in two parts: a private living area for the president of the College and a public/multi-purpose area with different rooms for the college. Open_2 total square footage is $1,930 \mathrm{Sq} . \mathrm{ft}$. 
Both Prototypes were designed and built with the BH Open-Built system, as part of the goal to construct adaptable, environmentally friendly net-zero homes.

For each of the two prototypes TRT were formed. These teams varied in size according to the stage of the project and were basically integrated by participants from MIT School of Architecture and Bensonwood Homes, and participants representing the clients (Open_1 and Open_2), industry partners and sponsors. Both the OPI's clients, CM Rehabilitation Center and Unity College became involved with the OPI through their connection with Bensonwood Homes.

\section{Interviews to OPI's principal stakeholders}

Semi-structured, open-ended interviews were conducted with key TRT coalition partners, focusing on member's perspective of team effectiveness in attaining OPI's goals, as well as on respondents' opinions about events that occurred during $\mathrm{O} 1$ and $\mathrm{O} 2$ processes (Yin, 1989). Although the interviews were open-ended and assumed a conversational manner, the interviewer followed a certain set of questions derived for the case study protocol (Yin, 1989).

\section{Stakeholders}

The four main sets of stakeholders making up the teams examined in this study were:

a) Department of Architecture Massachusetts Institute of Technology (MIT)

- House_n Research Consortium's director (MIT's director)

- House_n Research Consortium and "The Placelab" researcher 
b) Bensonwood Homes, Walpole, New Hampshire

- Bensonwood Homes' founder and owner (BH's owner)

- O1 project architect (BH O1 Architect)

- O2 project architect 1 (BH O2 Architect 1)

- $\mathrm{O} 2$ project architect 2 (BH O2 Architect 2)

- $\mathrm{BH}$ interior designer

- BH building system's representative who worked in O1 and O2 (BH BS)

- $\mathrm{BH} 3 \mathrm{D}$ designer

$\mathrm{BH}$ is an associated partner of MIT for $\mathrm{OPI}$ and is responsible for the design, prefabrication off-site, on-site construction, job and project management and supervision of the prototypes. Business magazines related to the construction industry affirm that $\mathrm{BH}$ represents the state of the art approach of OB system in USA. Every project undertaken by $\mathrm{BH}$ is addressed by a multidisciplinary in-house team of architects, designers, engineers, wood workers, building systems team specialists, working at BH Walpole's facility.

\section{c) Open_1 Crotched Mountain Rehabilitation Center (O1)}

- CM VP for finance and Advancement of CM Foundation (CM VP)

- CM Executive Director for Residential Services (CM ED)

- CM Medical Director (CM MD)

- CM Chief of Maintenance (CM MC)

- O1 Resident

- Ol Caretaker Resident 
CM's CEO, board of directors, administrators, brain injury specialists, physical therapists, voice therapists, physicians, patients' care-takers, and other health care professionals, work together as an efficient multidisciplinary team. CM is an environmental friendly institution working closely with its community and providing services to patients with brain injuries.

\section{d) Open_2 Unity House (O2)}

- Unity College President (O2 resident A)

- Unity College President's wife (O2 resident B)

- Associate Professor of Human Ecology

- Interim Sustainability Coordinator, Unity College

- Associate Director of College Communications, Unity College

Unity College is a small educational institution, educating "leaders of tomorrow" with the mission of protecting the environment. The college, the faculty' members, the board and the students are deeply committed to sustainability.

\section{Observations}

Direct observations during field visits to the case study "sites" provided extra data for the case study (Yin, 1989). On-site observations for this study ranged from formal to casual data collection activities and were collected in three settings: O1, O2, and BH's facility, providing information about the prototypes and about how the occupants use them. On-site observations conducted in BH facility afforded data regarding work 
methodologies employed by multidisciplinary teams involved in the design and construction of $\mathrm{O} 1$ and $\mathrm{O} 2$.

\section{Data analysis procedures}

Data analysis consisted of examining, categorizing, and recombining the evidence produced by data related to TRT's effectiveness in accomplishing $\mathrm{O} 1$ and $\mathrm{O} 2$ 's goals. Information was extracted from semi-structured open-ended interviews and on-site observations (Yin, 1989). The ultimate objective of this analysis was to treat the evidence fairly, to produce convincing investigative conclusions, and to exclude alternative interpretations (Yin, 1989). The principal strategy was to address the factors that enhance or hinder TR's effectiveness, tracing these variables throughout both case studies. Thus, Stokols' 'factors' (Stokols et al., 2008) were applied as theoretical propositions and were used as a guide to organize and to explore stakeholders evidence in connection with each case study and across both case studies (Yin, 1989). This multiple case study involves a complex and diverse set of variables affecting TR's effectiveness. A descriptive approach was used to identify the type of evidence to consider, and the overall pattern of complexity that was eventually used in a causal sense to 'explain' team success (Yin, 1989).

The investigator recorded in audio the interviews and then transcribed data verbatim into written format. Information supplied by participants in the interviews, as well as data obtained from on-site observations, was labeled with a keyword indicating categories, topics or common themes. Codes were assigned to units of meaning or 
inferential information compiled during the study, differentiating and combining the data retrieved.

Codes from the start list were revised and were changed as the analysis of data progressed; some codes did not work and others decayed. Others flourished too much and as too many materials fit them, they had to be broken down into sub codes (Miles \& Huberman, 1994). The investigator used a qualitative narrative to describe the analyzed themes and findings (Patton, 1990). (For Interview and Observation Diagram, see appendix, table 1, page X).

\section{Strategies for validating findings}

A pattern-matching logic strategy was used to prove the internal validity of this study. This strategy compares an empirically based pattern with a predicted one or with several alternative predictions (Yin, 1989). In this mode, factors described as affecting TR's effectiveness (Stokols et al., 2008) were used as metrics to evaluate OPI teams' grade of success in attaining goals. This study employed a nonequivalent dependent variables analysis (Yin, 1989) with Stokols' factors as the analysis' multiple dependent variables (Yin, 1989). A Likert-Type scale was designed to measure a) degrees of TR's effectiveness in accomplishing OPI's goals, and b) degrees of influence of predicted factors in TR's effectiveness. Metrics for measuring both variables were described as weak, moderate and strong. Data was analyzed using Stokols et al.'s factors (2008). Nonequivalent dependent variables influenced TRT effectiveness in OPI in the way predicted by Stokols et al. (2008). A different overall combination of factors was identified for both $\mathrm{O} 1$ and $\mathrm{O} 2$; a dissimilar pattern of factors produced a different level of 
TRT effectiveness, as predicted by Stokols et al. (2008). In addition, a theoretical replication was made across both cases studies (Yin, 1989). This analysis confirmed the hypothesis linking nonequivalent dependent disparate combination of factors with different levels of TRT effectiveness in attaining goals, as predicted by Stokols et al. (2008).

A similar pattern-matching analysis was conducted for the embedded units of analysis, which referred to the particular goals accomplished by each individual stakeholder. This analysis was first conducted within each case study. The outcomes were interpreted at the single-case level and were treated as one of several factors in a patternmatching analysis. The patterns for each case study were compared across cases, following the replication mode for multiple case studies. Finally, the conclusions drawn from both cases became part of the conclusions for the overall study (Yin, 1989).

One of OPI's goals was to take advantage of lessons learned in one prototype and to apply these to improve subsequent prototypes. To highlight changes, if any, between the first and the second prototypes, and to confirm validity and reliability of evidence collected in the open-ended interviews, repeated on-site observations were used as a secondary analysis approach. The repeated observations analytic approach is part of the time-series analysis (Yin, 1989) and was conducted on a cross-sectional basis in O1 and $\mathrm{O} 2$, to obtain first hand information about the degree of accomplishment on the embedded units of analysis (OPI's goals).

To improve the accuracy of the findings, the following strategies were used:
a) Triangulation of sources of information
b) Peer-scrutiny 
Nonetheless, the potential of bias in the collection and/or analysis of data from the interviews and on-site observations is always a factor in qualitative research.

\section{Limitations of the study}

The investigator was prepared to ask open-ended questions on topics associated with aging in place design to OPI's principal stakeholders. After conducting the interviews and on-site observations the investigator realized that one of the principal issues for further research was related to the organization, structure and leadership of the OPI' teams. According to the investigator's appreciation this fact influenced OPI's outcomes. At that point the investigator realized that TR gave an interesting conceptual frame to the study and decided to analyze the answers from this different point of view. Even though the interviewees were asked about the structure and organization of the teams, TR was never addressed as a topic during the interviews. This fact may constitute a limitation to the present study.

\section{Narrative Structure}

The qualitative analysis of the multiple case study report contains multiple narratives, presented as chapters or sections. The narrative structure was used in the description of the analysis by case studies and across case studies. The individual cases serve only as the evidentiary base for the study and were used in the cross-case analysis (Yin, 1989). Under each "factor" examples were drawn from both cases, but neither one is presented as a single case study. The narrative information was augmented with graphic displays (Yin, 1989). 


\section{RESULTS}

\section{Open_n Prototype Initiative, Transdisciplinary Collaboration, Team Performance and Criteria to Gauge TRT Effectiveness in Attaining OPI's Goals}

Studies in TR suggest that independent evaluation is critical for strengthening quality control. Team members may refuse or obstruct these practices, and may consider these controls as transgressions into other partners' fields of competence and assigned roles practices (Wiesmann, et al., 2008). The purpose of this study was to provide an independent evaluation of the OPI TRT effectiveness. Even though literature review in TR considers that there is no "one-size-fits-all set of contextual factors" that could be anticipated to exert similar levels of influence on collaborative outcomes for all research teams and settings (Stokols, et al., 2008), this study has identified a set of contextual factors with dependent variables that have directly influenced effectiveness in $\mathrm{O} 1$ and $\mathrm{O} 2$ team collaborations.

Academia, organizations, professionals, practitioners and industry joined efforts to build two distinct prototypes, $\mathrm{O} 1$ and $\mathrm{O} 2$. $\mathrm{BH}$ founder and owner declared $\mathrm{OPI}$ “is just beginning, it is not a very matured, perfected concept," noting "we are at the beginning of the beginning" (confidential, personal interview, 2009). Having only designed and built two prototype projects, all participants agreed that there is room for improvement. This study provides considerations that need to be taken into account when designing new collaborative efforts for Open $3(\mathrm{O} 3)$, which is presently being evaluated, as well as other collaborative efforts that address aging in place.

Team effectiveness in OPI could be evaluated in different ways and using different parameters. For example, assessing TRT effectiveness using the evaluation $\mathrm{O} 1$ 
and O2's accomplished goals as criteria, then outcomes are impressive. Evaluating TRT effectiveness using the opinions of teams' participants as criteria, OPI is a success, as all participants interviewed agreed this was so. However, if TRT success is analyzed using its success at full filling OPI's highest-priority goals as criteria, then its success is less significant. This study analyzes several factors that had direct influence and impacted on TRT effectiveness in accomplishing OPI's goals (Stokols, et al., 2008).

Even though most of $\mathrm{O} 1$ and $\mathrm{O} 2$ 's goals have been successfully attained, TRT were unable to accomplish some significant OPI goals. An analysis of data collected from on-site observations and from open-ended interviews, shed light on the goals that were not accomplished and account for possible reasons. First, TRT was unable to develop a cost-effective, prefabricated prototype. This was a goal established initially but never full filled in either prototype. $\mathrm{O} 1$ and $\mathrm{O} 2$ were described as "pre-prototypes" (confidential, personal interviews). $\mathrm{O} 1$ and $\mathrm{O} 2$ were part of a TR process that would allow for future cost-effective prototyping. However, insufficient funding, lack of creative industry partner collaborations, time and cost constraints, a prerequisite to design innovative solutions, and extremely high standards of production, prevented the first two prototypes of being cost-effective.

Second, OPI's goal of incorporating pervasive computing systems was not attained. Two main reasons account for the absence of this technological feature. While monitoring behaviors and ubiquitous computing systems were a highest-priority for MIT, TRT in $\mathrm{O} 1$ and $\mathrm{O} 2$ were interested in monitoring the environment and the energy efficiency of the homes, rather than in monitoring behaviors. Also, TRT's ethical, legal and privacy concerns prevented MIT from incorporating this type of research. MIT did 
not participate in research related to prototype's energy efficiency monitoring systems due to budget constraints, lack of appropriate funding and a dissimilar highest-priority ranking of goals. Nevertheless, since sustainability was one of OPI's main goals, industry sponsors provided energy efficiency monitoring systems to both prototypes.

Third, $\mathrm{O} 1$ and $\mathrm{O} 2$ did not accomplish the timeline scheduled for on-site prototype's construction. Several factors account for delaying the work schedule; from organizational factors, team readiness, and economic factors to weather delays. Multiple reasons made it impossible to design and built the prototypes in the specified, rigorous time schedule. Fourth, OPI aging in place design goals called for design based on universal design principles, yet $\mathrm{O} 1$ and $\mathrm{O} 2$ have no universal design solutions. $\mathrm{O} 1$ is handicapped accessible; while $\mathrm{O} 2$ is not. This study will analyze in further detail other reasons that can be accounted for these shortcomings.

Previous studies in TR suggest that factors influencing TRT effectiveness should be considered at the outset of any collaborative effort (Stokols, et al., 2008). Analysis identified several factors that were critical, constraining TRT effectiveness in $\mathrm{O} 1$ and $\mathrm{O} 2$ and preventing OPI from accomplishing $100 \%$ of its goals, specifically those that were not explicitly addressed in participatory meetings at the outset of the collaboration. The factors hindering TRT effectiveness were: 1) the lack of a designated OPI TRT top leader for both $\mathrm{O} 1$ and $\mathrm{O} 2 ; 2 \mathrm{a}$ ) the ill-defined content of stakeholders' common goals and $2 \mathrm{~b}$ ) the ill-defined highest-priority ranking of multiple stakeholders' goals and outcome expectations; 3) the lack of a clear pre-defined organizational structure; 4) OPI cost's considerations; 5) the insufficient industry partner's participation; 6) coalition partners' collaboration readiness; and 7) the lack of funding for $\mathrm{O} 2$ 
Analysis also identified several factors mentioned by Stokols et al. (2008) that also enhanced OPI TRT effectiveness. The positive factors were: 1a) the participatory goal setting and $1 \mathrm{~b}$ ) the TRT communication patterns; 2a) the TRT members' familiarity and $2 b$ ) their social cohesiveness; $3 a$ ) the coalition partners' transformational leadership traits and behaviors and 3b) BH's owner, MIT's director and BH's project architects transformational leadership skills; 4) the availability of funding for $\mathrm{O} 1$; and 5) the continuity of collaboration between researchers and practitioners. In this section, this study will further analyze the factors identified as enhancing or constraining OPI TRT effectiveness in attaining OPI's goals (Stokols, et al., 2008)

\section{Lack of a Designated OPI TRT Top Leader for Both $\mathrm{O1}$ and $\mathrm{O2}$}

Analysis of $\mathrm{O} 1$ and $\mathrm{O} 2$ interviews and on-site observations suggests that there was no specific designated head or team leader for O1 and O2 TR collaborations. An OPI TRT top designated leader for both $\mathrm{O} 1$ and $\mathrm{O} 2$ would have influenced individuals and groups within coalition organizations, helping them establish common goals and rank them using highest-priority ranking system. The top designated leader's role was to update, correct and verify the priority ranking of common goals at all stages of the initiative. Thus, the top designated leader would have guided TRT members towards the achievement of those goals, allowing them to be successfully achieved (Hackman, et al., 2004).

Most of OPI's principal stakeholders were interviewed for this study. In every interview two questions were consistently asked, and in every interview each stakeholder gave almost the same answers. The first question asked how multidisciplinary team 
members were recruited, and the second question asked who was the designated OPI's team leader. The first answer was that there was no formal "recruitment." Participants were invited to participate in the initiative on an ad hoc basis. The answer to the second question was that OPI had no designated team leader. BH's owner and MIT's director were the founders, but there was no OPI leader for $\mathrm{O} 1$ and $\mathrm{O} 2$. $\mathrm{BH} \mathrm{O} 2$ architect 1 affirmed that in many opportunities there was the need for TRT to have a leader who had the last word in decision making.

BH O2 architect 2 stated that MIT House n Research Project's director (MIT's director) was OPI conceptual team leader, and made the final conceptual design decisions for the TRT. BH O2 architect 2 affirmed that leadership was very important for the team's results, and added that "there must be a great sense of leadership in the project" (confidential, personal interview, 2009). He added that in BH's teams, it was not always the member who had the "big idea" or the "vision" who became the team leader, noting that this fact made "the team more effective" (confidential, personal interview, 2009).

- Example of Lack of a Designated OPI TRT Top Leader for Both O1 and O2 When researchers asked $\mathrm{BH} \mathrm{O} 2$ architect 2 about who was $\mathrm{O} 1$ or O2's team leader, he answered that although MIT's director and BH's owner were OPI's team leaders, "there was no one leader" per se for OPI, noting "I might have to give that some more thought" (confidential, personal interview, 2009). When asked the same question, $\mathrm{BH} \mathrm{O} 2$ architect 1 replied that nobody really knew who the team leader was, stating that ultimately BH's owner had the last word. She explained that it had been really difficult to make decisions when BH's owner disagreed on what the architects were doing, and even 
worse, if the two $\mathrm{O} 2$ architects disagreed on something, and added "that happened a lot" (confidential, phone interview, 2009). BH O2 architect 1, who was BH's LEED Platinum Certification specialist, stated that when it boiled down to making environmental decisions, "if anybody was in charge, I was. I don't know. I made a lot of those decisions" (confidential, phone interview, 2009)

Results of the content analysis of the interviews identified that both TR collaborations would have done much better with a designated person in $\mathrm{O} 1$ and in $\mathrm{O} 2$ to act as OPI's team leader, representing the interests of OPI as a whole and having the last word. An OPI's designated transdisciplinary team leader would have been relevant to the collaborative initiative' effectiveness; the lack of team leadership was the principal reason for not having accomplished all of OPI's goals, in both $\mathrm{O} 1$, and $\mathrm{O} 2$.

\section{Ill-Defined Content and Highest-Priority Setting of Multiple Stakeholders' Common Goals and Outcomes}

The ill-defined content of multiple stakeholders' goals and outcomes refers to $\mathrm{O} 1$ and $\mathrm{O} 2$ inconsistent process of identification of common goals, which later prevented the TRT of clearly identifying multiple stakeholders' highest-priority ranking of goals and outcomes. This process is critical to effective TR; with this information teams successfully tailor research to the unique and highest-priority goals of each stakeholder. This process allows TRT to identify various stakeholders' competing or project specific goals and interests. Participants are able to discuss dissimilar agendas and/or different priorities. 
Stakeholders' different agendas accounted for the TRT's difficulty in deciding a highest-priority ranking of common goals and outcomes. Even though TRT members "ideally" shared common goals, identified in face-to-face meetings and participatory goal settings; in reality, a contradictory highest-priority goal ranking set them apart. This critical variable was not clearly identified by TRT members in both $\mathrm{O} 1$ and $\mathrm{O} 2$, and directly affected team's ability to resolve problems in a manner that did not conflict with individual stakeholders' specific highest-priority goals and outcomes.

Results of the interview analysis suggest that O1's identified common outcome was the design of a house for brain injured patients transitioning from a hospital setting to a house setting. OPI's principal goals were shared by all TRT members (see Appendix). $\mathrm{BH}, \mathrm{MIT}$, and CM common goal was to design and build a green, energy efficient house, with Open-Built systems, allowing the house to be adaptable, flexible and easily updated. Underlying these common goals, however, were O1 TRT dissimilar agendas and different priorities.

BH's highest-priority was to develop a 3D Open-Built system's library with design and construction details. These design and construction details would serve as components and would be combined to form unique structures, linked to efficient prefabrication. MIT's top priority goals were 1) to develop design components that would provide adaptability to a home setting, making the environment responsive to occupants' changing needs and 2) to integrate pervasive computing systems as an as additional technological support to monitor changes in residents' behavior and/or changes in the environment. 
CM's top priority was to "provide accessible and affordable housing to those who acquired brain injury and had additional needs" (confidential, personal interview, 2009). $\mathrm{CM}$ wanted to develop a prototype house located within the CM campus, aesthetically integrated with the other CM campus buildings, that would allow for future replication, and would provide accommodation to brain injured patients that were transitioning from a hospital environment to a house environment; permanently or transitorily; alone or with family members; while providing housing for patients' caretakers (confidential, personal interview, 2009).

Issues concerning the ill-defined highest-priority ranking of goals and outcomes affected O2 TRT effectiveness in attaining O2 goals. BH Architect 1 expressed that different stakeholders had different priority ratings as well as "different agendas" (confidential, phone interview, 2009). Architect 1 emphasized that some members considered "net-zero" as the principal priority; other members "adaptability" and others "LEED platinum" (confidential, phone interview, 2009). Architect 1 expressed that at times, TRT's members did not agree on any rating of priorities.

Even though the OPI's overarching goals were shared by all major stakeholder participants, differences in the rating of highest-priority goals were noticed among organizations and even among members of the same team. The results of interview analysis suggested that the two architects within the BH's team had two different agendas. $\mathrm{BH}$ Architect 2 was involved in developing 3D drawings for reproducing a BH's market ready, prefabricated, and cost effective Unity House prototype. BH Architect 1 was the LEED certified specialist, and was more interested in accommodating O2 future residents' needs and goals. Even though OPI's main goals was to update the 
housing industries to accommodate the needs of aging in place populations, $\mathrm{O} 2$ principal stakeholders did not consider universal design a top priority, and agreed that $\mathrm{O} 2$ should be a "zero carbon home, ecologically exemplary and that could apply for the LEED platinum certification," (confidential, phone interview, 2009).

Examples of shared highest-priority goals include:

- Aging in Place and BH Open-Built systems

Open-Built systems of design and construction offer solutions to aging in place populations. The system provides adaptability, flexibility and accessibility; all OPI's main considerations. CM MD pointed out that the uniqueness of $\mathrm{O} 1$ was its "ability to be very flexible for a given client" (confidential, personal interview, 2009). He appreciated that the house could "change with a person's capabilities", and added that it could "also be flexible for the next client that comes in" (confidential, personal interview, 2009). He stated that "you can really remodel the floor plan in some different ways" (confidential, personal interview, 2009). CM MD emphasized the ability of the house to meet a person's needs with brain injury, "whether they are very physically independent or physically dependent" (confidential, personal interview, 2009).

In connection with BH Open-Built systems' characteristics, the director of CM ED expressed that, as a TRT member, when he had to make decisions; his decisions were based upon flexibility considerations. His objective was to have a home in campus that could be easily adapted to various uses, asking "what if questions" around ideas such as what if he wanted to use O1 "to accommodate children at one time and seniors at another 
time". CM ED affirmed that "I really tried to look at it in terms of not boxing us into one pathway,", while finding design solutions that could adapt the building to work for all "different licensures" (confidential, personal interview, 2009).

OPI's highest-priority goal of using BH Open-Built systems was a top priority goal for all stakeholders. BH Open-Built system was specified at the out set of the initiative, and was efficiently utilized in $\mathrm{O} 1$ and $\mathrm{O} 2$. TRT showed $100 \%$ effectiveness in attaining this common goal.

Examples of stakeholders' different highest-priority goals:

\section{- Team Initiatives}

Studies in TR suggest that multiple stakeholder groups define highest-priority goals of TR differently, thereby creating yet another challenge to the evaluation of team initiatives (Stokols, et al., 2008). In O1, TRT had this extra challenge. MIT gave high priority to the scientific, intellectual and technological integration of knowledge. Even though BH and CM recognized MIT's highest-priority goals, their weighting of top priorities was different. Although CM VP was appreciative of the intellectual platform MIT brought to the initiative, and proudly described $\mathrm{O} 1$ participatory meetings as "a research forum with academia, organizations and industry" where he was able to meet "so many interesting people, good thinkers", intellectual development was not CM's highest-priority goal (confidential, personal interview, 2009). MIT's participation afforded TRT "the academic world point of view as well as MIT's industry connections," 
CM VP expressed, noting that MIT's director "represented not only the academic world but also the future" (confidential, personal interview, 2009). In this context, CM VP stated that MIT's objective was "to spark an interest in young people to move the housing industry forward," stating that even though MIT's goal was very valuable, it was not CM's top priority.

- Integration of Pervasive Computing Systems

Even though the integration of pervasive computing was part of the participatory goal setting and had highest-priority ranking for MIT, "Mites" or sensing devices were not used in $\mathrm{O} 1$ or $\mathrm{O} 2$ prototypes. OPI's stakeholders account various reasons for the absence of this technological component. MIT's director expressed that both prototypes were located too far away from MIT to make them "kind of the research platform" that they had hoped for, explaining that to manage a behavioral research process with "Mites," researchers had to conduct follow ups and do regular visits to the research sites.

The CM VP expressed that originally, they were interested in technology to control indoor air quality. CM played around MIT with that idea but MIT "was not interested in investing time into it" (confidential, personal interview, 2009). Ol's architect stated that $\mathrm{BH}$ wanted to find a relevant use for MIT's research applications and that they were many "privacy concerns" in $\mathrm{CM}$ to have $\mathrm{O} 1$ become a perfect match (confidential, personal interview, 2009). He added that $\mathrm{BH}$ was interested in having MIT researchers work in "environmental sampling;" but that MIT as a research institution needed a fairly large investment to make things happen off-site (confidential, personal interview, 2009). The architect finally decided that it was not a good match for CM to 
come up with funding for that purpose. The application of MIT's pervasive computing system in O1 is an example of how MIT's highest-priority goal lost its top priority ranking, as it was weighted against variables such as distance, funding, and privacy concerns.

- Examples of Handicapped Accessibility, Universal Design and LEED Platinum Certification in $\mathrm{OI}$

Literature review in TR indicate that the evaluation of TRT's initiatives should incorporate metrics that give the greatest weighting to the highest priority goals specified at the outset of the initiative by major stakeholder groups (Stokols, et al., 2008). One of OPI's highest-priority goals was to develop design solutions for populations changing needs. In $\mathrm{O} 1$ this requirement addressed brain injured patients' changing needs. Evaluation of OPI TRT highest-priority rating in reference to the application in $\mathrm{O} 1$ of universal design principles illustrates another instance where ill defined content and lack high priority ranking interfered with reaching important goals.

By definition universal design refers to "the design of products and environments to be usable by all people, to the greatest extent possible, without the need for adaptation or specialized design" (NC State University, 2006). At the outset of O1, accessibility was one of the principal considerations. As $\mathrm{O} 1$ progressed, accessibility was sacrificed because of cost, size of the house, and carbon footprint issues. In $\mathrm{O} 2$, accessibility was set aside by size and prefabrication issues. 
In $\mathrm{O} 1, \mathrm{CM}$ requested that the design of the house follow universal design principles. The director of residential services desired that TRT go beyond the specifications of the ADA code, insisting in multiple occasions "let's go above and beyond because ADA code doesn't always necessarily translate to accessibility for our clients" (confidential, personal interview, 2009). The architect explained that the director was essential in helping him understand that "sometimes spaces that are great for somebody in a wheelchair aren't great for somebody learning how to walk" (confidential, personal interview, 2009). While the TRT had to answer to the brain injury team and provide the basic level wheelchair circulation, the TRT also "had to map out a little bit of a plan for other uses of that space" (confidential, personal interview, 2009). The architect reflected on the effectiveness of the team's efforts adding "how we did on that I guess the next residents will tell us" (confidential, personal interview, 2009).

The chief of maintenance affirmed that originally they requested 42 " wide doors, as part of their top priority goal ranking. The TRT had to compromise when they were "starting to deal with square footage and the costs were going up like crazy" (confidential, personal interview, 2009). He added that in a decisive moment CM had to make a decision and settled for 36" wide doors. O1's architect suggested that the decision was made at the end of significant discussions, and that he recalled that the concept behind the critical decision was that $\mathrm{Ol}$ was a transitional home. Residents are coming out of a hospital environment where the doors are 42"wide, heading towards homes where the norm is a 36 " wide doors. Another consideration was that by choosing to have 36 " wide doors the building could be smaller which would "help keep the footprint of the building back to where it needed to be" (confidential, personal interview, 2009). This 
compromise reflects upon the value assigned to universal design principles when compared to other project considerations.

On-site observations were conducted on O1. Analysis of the on-site observations allowed the investigator to check TR's team effectiveness in making the decision on the 36 ' wide door against the 42 " wide doors. In this specific case, universal principles would recommend 42" wide doors. During the on-site observation, O1's architect provided a guided tour of the house. CM VP and the chief of maintenance were also on the tour. Photos of $\mathrm{O} 1$ were taken and the conversation recorded at all times. The architect described the kitchen layout, suggesting that the design was conceived to provide wheelchair accessibility "to all the functions," insisting that people could make their own food, use their own sinks and move things up and down in the kitchen cabinets.

The resident who first moved into $\mathrm{Ol}$ listened to the conversation. He kindly interrupted the architect's explanation to affirm that the house "is absolutely beautiful." However, he affirmed that "there is one thing that I would say immediately," and added that since he used a really wide wheelchair, the doors were "much, much too narrow." $\mathrm{He}$ explained that "getting through these doors is a problem" (confidential, personal interview, 2009). The architect responded that he could see there were some marks on the side of the door frame.

OPI had at the core of its conception that clients and end users were part of the design team. OPI's goal is to respond to aging population's changing needs. The TRT's decision about the width of the doors shows an error in the TRT's highest-priority ranking. The resident continued to point out that the doors have "to be wider, definitely" and that the design of the kitchen was not wheelchair accessible. He explained that when 
"trying to get up to the counter you bang your knees" and that "there is no way I could make a meal for myself, I hate to say it but it is true. He then added that "you really have to take this into consideration" (confidential, personal interview, 2009), and suggested that the kitchen design had to be re-thought as far as wheelchair accessibility, and that he would gladly volunteer to participate in the design team to improve accessibility issues in the design of the house, which he insisted "was beautiful" (confidential, personal interview, 2009).

The interpretation and evaluation of the "door width" problem would be an "uncertainty" as described by literature in TR (Stokols at al, 2008). TRT members assigned different degrees of importance to this uncertainty, which lead to divergent assessments of the need and course of action. From a prioritization perspective, the TRT committed an error. This study suggests that the TRT did not rate effectively the priority and importance of universal design. TR in aging in place, analyzed from a sustainable perspective, should go beyond ADA requirements incorporating universal design principles in every prototype.

- Examples of Handicapped Accessibility, Universal Design and LEED Platinum Certification in $\mathrm{O} 2$

$\mathrm{O} 2$ 's Resident A stated that for $\mathrm{O} 1$, accessibility requirements was crucial, and added that the whole idea "behind O1 planning was accessibility" (confidential, phone interview, 2009). For O2, he noted that the "TRT had a very different set of goals, having in mind specifically a house for zero carbon print" (confidential, phone interview, 2009). For Unity House, he noted, the handicap issue was 
simply one more consideration, "like it would be for any place, you know, just to make sure it is accessible, that's all" (confidential, phone interview, 2009). He then suggested that $\mathrm{O} 2$ accessibility "wasn't an issue really for the planning of this house the way I understand it" (confidential, phone interview, 2009).

O2 Resident B expressed in a phone interview that the net-zero, LEED platinum certified $\mathrm{O} 2$ works beautifully, showcasing design solutions allowing changes in the spaces, converting in a few minutes from a single family house to a classroom or a gathering room for Unity College's board meetings, and enabling residents to host events, with seating up to 60 people. Her only concern was that Unity House was only handicap accessible in summer when the big glass doors could be opened.

The analysis of interviews and on-site observation of Unity House indicated that even though the house has two entrances, neither one is handicap accessible (confidential, phone interview, 2009). The front door could be accessible because, responding to LEED requirement it is elevated 8 " from the ground level. "Right now the house is inaccessible to a wheelchair" declared $\mathrm{O} 2$ Resident $\mathrm{B}$, stating that "the landscape has to be changed to make this house accessible." The O2 Resident B suggested that OPI might have gotten away with the accessibility issues because "it is an experiment" (confidential, phone interview, 2009).

Universal design recommends integrating a step less entrance to the site design, using site grading, earth work and sloping walks at 1:20 maximum slope, and avoiding ramps if possible. If ramps are used, they should be integrated to the design. On the other hand, the BH's Architect 1, specializing in LEED requirements, affirmed that LEED certification required the siding to be 8 " off the ground, because of snow. She added that 
"responding to a durability issue, you cannot have a floor even with ground in the Maine climate, so you need to have some kind of a moveable ramp to make it accessible and presently there is no ramp going to the house" (confidential, phone interview, 2009).

$\mathrm{O} 2$ is specially designed to feature design solutions that make for quick and easy space adaptations. Even though the TRT wanted to have at least one bathroom that was accessible, $\mathrm{O} 2$ has no bathroom handicapped accessible. BH's $\mathrm{O} 2$ Architect 1 suggested that a critical decision made by the TRT to favor the prefabrication of the "mechanical bar," diminished the surface available for the guest bathroom. This area of the house was prefabricated in the factory and transported to the site as one big part; it included the guest bathroom, the kitchen, the mechanical room, the master bedroom walk in closet and the master bathroom.

BH's O2 Architect 1 noted that "it came down to a space issue, like trying to squeeze this mechanical bar as small as we could make it" (confidential, phone interview, 2009). She then explained that in order to have an accessible bathroom, the TRT had to make the open-built 3D module which contained the bathroom and the mechanical room 4 feet longer, and they decided against that (confidential, phone interview, 2009). "So we tried and we failed, I guess," declared BH's O2 architect 1, "we wanted the guest bathroom to follow universal design, but even though we tried, it did not quite make it", noting that the TRT could not install a handicapped shower in the guest bathroom because of space constraints (confidential, phone interview, 2009).

Results of content analysis and on-site observations confirm that although the guest bathroom's sink is accessible; "there is a five foot circle in there, everything in the design is very tight" (BH's O2 Architect 1, confidential, phone interview, 2009). The 
architect confirmed that similar space considerations affected the master bathroom's design, where there was not enough room to install an accessible door (confidential, phone interview, 2009).

Results of interview analysis and on-site observations demonstrate that the weighting of the priorities assigned to OPI's goals in both prototypes was different for each stakeholder involved. For example, BH's owner and O2 Architect 2's prefabrication and 3D grid agenda, along with BH's O2 Architect 1's LEED certification requirements prevailed over OPI's aging in place, universal design's considerations. This study has pointed out important decisions made against TR's goals stated at the beginning of the initiative. BH's $\mathrm{O} 2$ Architect 1 suggested that even in $\mathrm{O} 2$, where universal design principles were an important design consideration, at the time of making decisions; the decision was made in favor of LEED certification requirements. She explained that she did not make her decisions based upon universal principles, or accessibility issues, because these only "serve such a small fraction of the population's needs". She then added "probably the house is not working exactly the way it was supposed to" (confidential, phone interview, 2009).

In $\mathrm{O} 1$ and $\mathrm{O} 2$ it is apparent that the priority rating changed along the way, and that a new set of priorities replaced previous one. Even though there are very rational explanations for the new set of priorities, questions arise if the new set of priorities is more valid than the old one, or if it is just a manifestation of a desperate response to contingencies. If this is the case, then the new set of priorities only serves to diminish the effectiveness of the TRT's performance. It is not clear which of these two considerations 
apply. Regardless, priority ratings should be clearly established at the beginning of the initiative and should be reconsidered and re-evaluated across the different phases of research (Stokols et al., 2009), as well as when new members get involved in the TR project. If conflicting agendas are not identified during the participatory goal setting, differences in highest-priority ranking of goals affect team effectiveness, as shown in O1 and $\mathrm{O} 2$.

\section{Lack of a Clear Pre-Defined Organizational Structure}

A clear, well-defined organizational structure is very important to the overall success of a team. This structure gives support to the team management, and defines decision making styles and problem solving strategies (Hackman \& Johnson, 2004).

Analysis of interviews indicates that TRT in $\mathrm{O} 2$ were not well organized and this fact affected team's effectiveness. BH O2 architect 1 suggested that a structure "would have helped when faced with making a tough decision," noting that many times, "no organizational structure or support existed for decision making" (confidential, personal interview, 2009). She affirmed that the difficult part about the design process was that "it seemed like there was no structure in place that identified who had the final say in something, on how decisions were going to be made" (confidential, phone interview, 2009).

BH O2 Architect 1 declared that she was especially concerned about the lack of an organizational and decision making structure, and suggested that this fact could partially be accounted for the long time the design processes took. In traditional setting owners make the last decision. Since BH was ultimately paying for the difference 
between market cost and prototype cost, OPI's decision making process was different. BH $\mathrm{O} 2$ architect 1 stated that BH's owner guided clients' decisions by giving options from which to choose; and clients made choices from within BH's selections.

In spite of this fact, the design process for $\mathrm{O} 2$ took over a year to complete, and "it was crazy, and it went on and on" (confidential, phone interview, 2009). O2 Architect 1 stated that the TRT was "trying to do too many new things, we might have just focus on one thing; we were trying to do everything new" (confidential, phone interview, 2009). BH She insisted that the decision making process was not clear (confidential, phone interview, 2009). She declared that for the decision making there "needed to be a clear structure about how decisions were made," and "the certitude that other members would honor those decisions" (confidential, phone interview, 2009).

$\mathrm{BH} \mathrm{O} 2$ Architect 1 insisted that there should have been pre-designed rules regarding the fact that once decisions were made, there was no other TRT's member that could override that decision. "But that happened constantly in this project," concluding that in a traditional setting the client had the last word, "whether you agree or not" (confidential, phone interview, 2009). For future initiatives, BH O2 Architect 1 recommended to discuss TRT organizational structure as part of the participatory goal setting, and design a structural support, with organizational principles to support decision making and problem solving (confidential, phone interview, 2009). 


\section{Cost Considerations}

Previous studies affirm that TR is not uniformly cost-effective (Stokols et al., 2008).

- Examples of Cost Considerations in $\mathrm{O} 1$ and $\mathrm{O} 2$

$\mathrm{BH}$ had to invest its own resources to collaborate for the successful completion of $\mathrm{O} 1$ and $\mathrm{O} 2$. BH's agreement with $\mathrm{O} 1$ and $\mathrm{O} 2$ owners' established that $\mathrm{BH}$ would receive as compensation a fee for design and construction services which would be equivalent to the market value of $\mathrm{O} 1$ and $\mathrm{O} 2$ buildings, and that $\mathrm{BH}$ would pay for any other investments related to the prototype's research (confidential, personal interview, 2009). BH O2 Architect 1 expressed that some project decisions were influenced by budget constraints (confidential, phone interview, 2009). BH SB expressed that "this project cost $\mathrm{BH}$ a tremendous amount of money, and decisions were made favorable to our budget or lack of budget" (confidential, personal interview, 2009).

Almost all of the OPI's participants interviewed declared that prototypes were not the greatest combination of the lowest possible cost and the highest possible quality. A BH SB expressed that the cost of prototypes exceeds what the end product would cost and is more expensive than market prices. He stated that "when the prototype goes into serial production, the end quality will improve, as new ideas will be applied to lower the costs and making the product cost-effective and accessible to the general public" (confidential, personal interview, 2009).

Prototypes' real costs surpassed cost estimations. BH SB suggested that as BH was a high end company with high quality control standards, those same standards 
applied to prototype's developments eventually may prove to be not cost-effective (confidential, personal interview, 2009). $\mathrm{O} 1$ and $\mathrm{O} 2$ cost considerations were not OPI's first priority. OPI's objective for the two first built prototypes was to develop unique buildings that would stand as symbolic flagships for OPI and for both the clients' organizations, showcasing as many OPI's design features as possible (confidential, personal interview, 2009). In this context and in view of OPI's TRT high expectations, BH O1 Architect suggested that it was a difficult responsibility to control the costs of $\mathrm{Ol}$ (confidential, personal interview, 2009).

The interviewees confirmed that even though all TRT's members were extremely satisfied with the results, the prototypes have proven to be "money losses for the people doing it and over budget for the people getting it" (confidential, personal interview, 2009). As studies in TR suggest, investments in TR, such as OPI, have to become more strategic and cost effective, especially in the light of the economic recession, significantly affecting the housing industry. Industry's participation and agencies sponsorship should be explicitly specified at the beginning of the collaborative effort.

\section{Industry Partner's Participation}

Literature review affirms that team science initiatives, such as the OPI, are not uniformly cost-effective, depending on certain contextual circumstances (Stokols, et al., 2008). Results of the interviews' content analysis and the on-site observations confirmed these previous findings. One of the main ideas of OPI was to create an initiative that would motivate the industry to get involved in developing a different model of the house of the future. The circumstances surrounding $\mathrm{O} 1$ and $\mathrm{O} 2$ were different. 
- Examples of Industry Partners' Participation

BH's owner affirmed that in O1, OPI invited the industry, getting a good reaction to that invitation, which translated in "a pretty broad participation, primarily suppliers and sponsors giving materials and equipment" (confidential, personal interview, 2009). "Lightolier did all the lighting fixtures, windows came from Lowland, and Certainty did the roofing and siding" (confidential, personal interview, 2009).

$\mathrm{O} 2$, however, was built during an economic recession. The recession hit $\mathrm{O} 2$ hard, as five or six industry sponsors left the initiative, and cut sponsorship of O2 (confidential, personal interview, 2009). BH's owner affirmed that OPI could not do without really good, committed sponsors (confidential, personal interview, 2009). BH O2 Architect 1 confirmed that due to budget restrictions and lack of appropriate sponsorship, she had to replace a completely designed lighting project "that went well over budget", providing another solution. She stated that the new design consisted of energy efficient fixtures and hard wired compact fluorescent lighting bought at Home Depot (confidential, phone interview, 2009). BH's owner affirmed that "we could not do what we needed to do on our own" (confidential, personal interview, 2009).

BH's owner considered that OPI not only needed sponsors' money, but their input and creativity as well, noting that BH's teams had ideas and creativity, but they could not think for industry partners. He added that OPI would not bring innovation to the industry unless the industry partners got involved, and expressed his disappointment with the lack of ideas provided to OPI's teams by industry partners (confidential, personal interview, 2009). 


\section{Coalition Partners' Collaboration Readiness}

Literature review in transdisciplinary research suggests that collaboration readiness factors and the presence of institutional support for cross-disciplinary collaboration strongly influence team's effectiveness (Stokols et al., 2008).

- Examples of Coalition Partners' Collaboration Readiness in Ol and O2

A BH building systems $\mathrm{O} 1$ and $\mathrm{O} 2$ team member stated that it was a difficult task to keep all the stakeholders' members up to speed all the time, and more so that the OPI needed special attention and "some of the other team participants were working on various projects simultaneously and could not make important decisions promptly" (confidential, personal interview, 2009). By the time these members were able to dedicate time to solve urgent problems, decisions were made by other TRT's participants that potentially conflicted with what they would have liked to see (confidential, personal interview, 2009). Coalition partners' participation should be clearly specified at the outset of the initiative to prevent delays caused by differences in team members' readiness.

\section{Participatory Goal Setting}

In participatory goal setting, stakeholders' dissimilar agendas are identified. The objective of a participatory process is to allow the formulation of clear goals, to prioritize goals and outcomes, and to avoid future conflicts in the understanding of common points and differences between stakeholders' organizations and between team members (Stokols, et al., 2008). As literature review in TR suggests, this participatory goal setting 
should be developed at the outset of the initiatives, in face-to-face meetings, to favor communication and enhance trust.

\section{- Examples of Participatory Goal Setting}

Participatory goal setting meetings were held for $\mathrm{O} 1$ and O2. TRT used group brainstorming in face-to-face meetings. Brainstorming was used to promote collective efficacy, and team performance. Face-to-face meetings were used to enhance good communication among team members, encourage feelings of inclusiveness, and enable teams to better manage issues of size, compatibility and cohesion. In O1, where the size of the TRT was very large, members recalled that a weekend retreat was held; team members from MIT, BH, and CM met to analyze stakeholders' goals and priorities, and to favor face-to-face communication.

In the $\mathrm{O} 1$ participatory goal setting meetings, $\mathrm{CM}$ VP suggested that great communication skills were necessary to discuss the points of view of all CM stakeholders. He referred that to put together a list of goals and outcomes that would reflect CM's requirements, the TRT had to discuss diverse CM stakeholders' agendas.

Each agenda gave a different highest-priority rating to design solutions addressing the patients' needs, the patients' caretakers and families' opinions, as well as the opinions of the board members, the physicians, the physical therapists, the occupational therapists, the speech therapists, the brain injury teams, the assisted technology specialists; $\mathrm{CM}$ directors, administrators, maintenance, and management; master planning specialists, licensing specialists, codes compliance specialists, fire safety engineers, and funding organizations. 
CM's goal was to provide the community with a new concept of residential housing. The house had to accommodate different patients as well as patients with different needs (confidential, personal interview, 2009). Since CM's requirement program offered an innovative concept of rehabilitation treatment which included housing, this new program needed to be defined, analyzed and explained to all parties involved. Ol's interviewees stated that this was a difficult process which took many meetings and involved multiple stakeholders (confidential, personal interview, 2009).

CM stakeholders' opinion was divided; a big group requested that $\mathrm{O} 1$ should be built more a "hospital-like" housing, while another opted for a more traditional house, with user friendly universal design features, that would "feel like home and not like a hospital" (confidential, personal interview, 2009). Thus, at the outset of OPI, CM stakeholders were divided in two groups, each group adhering to a different proposal or "agenda."

Results of the interview analysis suggest that during O1 TRT meetings, the team discussed stakeholders' different proposals. Each proposal responded to a different priority rating of requirements, thus implying a different design solution. As a $\mathrm{CM}$ foundation's VP recalled it was impossible to have all CM's stakeholders agree. CM CEO made a decision to an $80 \%$ consensus for any binding decision (confidential, personal interview, 2009). BH O1 Architect stated that at all times he was "trying to navigate a pretty large family of people" comprised of CM's various' departments representatives, telling him who was the stakeholder he should be listening to and who should be making the final decisions (confidential, personal interview, 2009). 
Previous studies in TR state that negotiation skills are essential in participatory goal setting meetings. MIT's participation in OPI supported innovation. MIT was responsible for research related to technological advances in OPI's prototypes. In reference to negotiations required among TRT participants in participatory goal setting, and priority ranking of goals meetings, $\mathrm{BH} \mathrm{Ol}$ Architect gave several examples. He explained that CM's project was developed "low tech", probably not fulfilling MIT's expectations. He expressed that MIT might prefer a more "glass box, Dwell magazine, home of the future" architectural style (confidential, personal interview, 2009).

The BH O1 Architect affirmed that what brought innovation and "was probably revolutionary about $\mathrm{O} 1$ was about the process," and not just about "that the house might look different" (confidential, personal interview, 2009). In reference to the participatory goal setting, he added that all stakeholders shared the common goal of developing a home that was as environmentally friendly as possible, considering the challenge that $\mathrm{O} 1 \mathrm{had}$ many features found in a hospital's environment, and to create the home with a really different process, with features designed to enable the house to do different things, "but look and feel like a home" (confidential, personal interview, 2009). In opposition to MIT's preference, an important part of CM's agenda was that the house integrated into the built environment, along the other campus' buildings. O1's architect suggested that O1 was designed with a "sort of camouflage element to fit in the campus" (confidential, personal interview, 2009).

Even though in $\mathrm{O} 1$ and $\mathrm{O} 2$ coalitions participatory goal setting was used to identify common goals and desired outcomes, and to analyze stakeholders diverse and 
often competing interests; team effectiveness suffered as participants' organizations only reached partial consensus on top desired goals and outcomes' priority rankings.

\section{Communication patterns}

Research conducted on group dynamics state that adequate feedback and communication favors effective team performance. Good communication among TRT members promotes feelings of trust and allows teams to better cope with issues of size, compatibility and cohesion (Stokols, et al., 2008).

- Examples of Communication Patterns

Analysis of interviews shows that trust between $\mathrm{O} 2$ team members was established long before OPI's developments. BH O2 Architect 1 affirmed that $\mathrm{O} 2$ residents "were really willing to be guinea pigs and they entrust it us $100 \%$ " (confidential, phone interview, 2009). O2 Resident A stated that "we trusted them and they came through for us" (confidential, phone interview, 2009). Literature review in TR suggests trust facilitated communication, allowing for the exchange of messages for clarification and feedback between fellow members and enhancing team effectiveness.

\section{TRT Members' Familiarity and Social Cohesiveness}

Recent reviews of research on team effectiveness suggest that increased familiarity among TRT members as well as greater social cohesiveness boosted productivity (Stokols, et al., 2008). An advantage of both O1 and O2 TR was the social 
and geographic cohesiveness of the stakeholders' participants and the familiarity among most team members. In both prototypes, the geographic scope of the TR collaboration ranged from local groups to regional groups, as most TRT members were from the New England area. In OPI's stakeholders' organizations, strong network ties formed among members since team participants shared demographic, geographical and educational similarities (Stokols, et al., 2008).

Besides the BH's members, in O1 the TRT was integrated by a cohesive group of participants from CM's organization. This large group consisted of CM's stakeholders; among them CM's CEO, CM Foundation's VP, board members, administrators, directors, physical therapists, voice therapists, physicians, brain injury staff, code consultants, licensure consultants, etc. CM team members' familiarity and social and geographical cohesiveness enhanced OPI's team productivity.

Example of TRT Members' Familiarity and Social Cohesiveness.

In $\mathrm{O} 2$ the TRT was integrated by several participants that shared a long lasting friendship and familiarity. O2's residents are the president of Unity College (O2 Resident $\mathrm{A}$ ) and his wife (O2 Resident $\mathrm{B}$ ). The husband is a long time friend of the owner of $\mathrm{BH}$. They have played basketball together for more than twenty years. The wife is a friend of one of BH's project architects (BH O2 Architect 1), who is an environmental expert and a LEED certification consultant with a wide array of experience in green design. For more than three years, they had worked together, teaching a class of green design for educators at Antioch University, in New England. They talked many times about the characteristics of the house that the architect would build for her friend. When Unity College decided to 
build a LEED Platinum certified project for Unity House, the natural decision for them was to hire the services of $\mathrm{BH}$.

Studies in TR observed that familiarity among team members may have a negative impact on team performance with the passage of time (Stokols, et al., 2008). O2's Resident A mentioned that even though he was aware that in certain cases when there is a friendship relationship, friends sometimes get less attended to because the other part knows "that you are their friend," he did not think "that their close relationships really affected the actual business partnership or the contract as such" (confidential, phone interview, 2009).

$\mathrm{BH}$, along with MIT's conceptual support, designed and built $\mathrm{O} 1$ and $\mathrm{O} 2$. Thus, OPI's TRT was integrated, in a big proportion, by employees from BH's divisions. Designers, engineers, general contractors, wood workers, architects, project managers, systems building personnel, and other BH multidisciplinary team members worked together on a daily basis in BH's Walpole facility. Arguably, the increased familiarity among BH's team members, as well as their great social cohesiveness, led OPI TRT to an increased productivity.

\section{The Coalition Partners' Transformational Leadership Traits and Behaviors}

Literature review in TR affirms that continued collaboration among groups of stakeholders along with a transformational leadership style enhanced team's effectiveness (Stokols, et al., 2008). Results of the content analysis of the interviews and on-site observations demonstrate that in the opinion of all OPI' principal stakeholders, $\mathrm{O} 1$ and $\mathrm{O} 2$ had been great successes, and accomplished most of their goals. OPI's effectiveness 
in attaining OPI's goals was due principally and foremost to the fact that each of the stakeholder organizations had a long tradition in multi, inter or transdisciplinary collaborations and that most of coalition partners shared a transformational style of leadership.

- Examples of Coalition Partners' Transformational Leadership Traits and Behaviors

OPI's leaders shared characteristics of personality found on TR's transformational leaders (Stokols et al., 2008). OPI's leaders had personal traits of intelligence, self-confidence, high educational status, task-relevant knowledge, sensitivity to members" socio-emotional needs along with "good physical appearance" (Stokols, et al., 2008). Studies show that a transformational leadership style has proven critical to the implementation and maintenance stages of the coalitions as well as it outcomes. All OPI's inter-organizational coalition leaders, such as BH's owner, MIT's director, CM's executives and Unity College's president, are very well respected partners among TRT. As suggested in TR literature review, having "champions" who are respected among partners leading inter-organizational coalitions facilitate TR collaboration (Stokols, et al., 2008). Leaders' personality and behavior greatly influenced collaborative developments and results, and TRT effectiveness. 


\section{BH's Owner, MIT's Director and BH's Project Architects Leadership Traits and}

\section{Behaviors}

Previous studies in TR indicate that the empowering style of transformational leaders benefit TRT effectiveness (Stokols, et al., 2008).

Examples of BH's Owner, MIT's Director and BH's Project Architects Leadership Traits and Behaviors

BH's owner and MIT's director shared a transformational leadership style. As leaders, they created OPI's agenda by establishing a direction and creating a vision for the future, and by developing a human network for achieving OPI's agenda. They further developed the network for achieving that agenda by communicating their vision among OPI's stakeholders and aligning industry partners and sponsors.

BH's owner and MIT's director created teams and coalitions that understood the Open Source Building Alliance vision and the strategies for updating the housing industries, and accepted the validity of OPI's approach. They executed OPI's agenda by motivating and inspiring TRT, with the basic and profound goal of advancing the housing industries, and developing successful innovations for aging in place populations.

BH's in-house project architects were $\mathrm{O} 1$ and $\mathrm{O} 2$ project architects. $\mathrm{BH}$ 's architects were inspired by BH's owner transformational leadership style; they shared his vision and his sense of mission. They were effective at building trust and respect among fellow team members. $\mathrm{O} 1$ and $\mathrm{O} 2$ project architects had management and leadership skills. Even though leadership and management were essential to the overall success of the TRT, they were not the same; while management produced organized and systematic 
results, leadership often lead to useful change in the design process, in the $3 \mathrm{D}$ library, in the prefabrication system, and in environmentally friendly decisions for $\mathrm{O} 1$ and $\mathrm{O} 2$ (Hackman \& Johnson, 2004).

A critically important factor greatly contributing to the success of $\mathrm{O} 1$ and $\mathrm{O} 2$ was the transformational leadership characteristics of the founder and owner of $\mathrm{BH}$. BH's owner, as a leader, is supportive, democratic, empowering, committed and encourages cooperation, engaging the support of others. This style significantly enhanced OPI TR collaborations in both university and community settings (Stokols, et al., 2008). O2's Resident B defined him "as incredibly charming" (confidential, phone interview, 2009). BH' owner has an empowering leadership style which boosted team efficacy. During the on-site observations conducted at $\mathrm{BH}$, the investigator was able to perceive the pride and member satisfaction of BH teams and their professionalism. This leadership style translates as well into providing first rate facilities, such as BH's spacious, clean state of the art Walpole facility, with its computerized machinery and 3D library.

$\mathrm{BH} \mathrm{O} 1$ and $\mathrm{O} 2$ architects were managers of their teams and created the prototype's planning and budgeting agenda. They further developed a human network for achieving the agenda, and executed the agenda by controlling and problem solving. BH's owner declared "the project architect was an integrator" (confidential, personal interview, 2009). Project architects had to produce OPI's desired outcomes with a degree of predictability and order, and consistent with key results expected by stakeholders (Hackman \& Johnson, 2004). BH's transformational leadership style enhanced TRT effectiveness. 


\section{Funding Issues}

Investments in team science need to be supported by private and public funding (Stokols, et al., 2008). $\mathrm{O} 1$ and $\mathrm{O} 2$ were labor-intensive, and even though both initiatives were not cost-effective, $\mathrm{O} 2$ was extremely affected by the effects of a global economic recession.

- Examples in Funding Issues

Funding was a big consideration for OPI's stakeholders. O1 had funding from many different agencies, and the agencies "loved the project." CM's CEO, CM VP, CM's administrators, staff and directors had elaborated a list of requirements for $\mathrm{O} 1$ in the understanding that the house to be built should be widely accepted by funding agencies. This list was discussed multiple times within the TRT. The O1's administrator declared that it would not have been helpful for CM to build "something" that would not ultimately "get funding support for the services provided in that house" (confidential, personal interview, 2009).

$\mathrm{O} 1$ had the necessary funding, while $\mathrm{O} 2$ lacked sufficient funding to support initiative's costs. Several ideas included in $\mathrm{O} 2$ first proposals were not developed in $\mathrm{O} 2$ due to lack of funding (confidential, personal interview, 2009). O2 Resident A expressed that even though he was not interested in MIT behavioral research, he would have been interested in MIT's collaboration for the installation of a computer based internal monitoring system that measured the energy efficiency of the house. O2 Resident A expressed his disappointment that MIT would not participate with the TRT developing a project to measure the efficiency of the house, and declared that it was clear to him that 
MIT did not have any financial support, affirming that "Unity College was not willing to pay for MIT's high tech approaches" (confidential, personal interview, 2009). TR is not uniformly cost-effective; investments to be specified during participatory goals setting and supported by private and public funding (Stokols, et al., 2008).

\section{The Cost-Effectiveness Considerations in OPI TR}

Literature review affirms that team science initiatives, such as the OPI, are highly labor-intensive, suggesting that the effectiveness of team science is extremely variable, not uniformly cost-effective, depending on certain contextual circumstances (Stokols, et al., 2008). In financial terms, several TRT's participants suggested that for them OPI was not cost effective. Literature review in TR suggests that TR requires other types of compensation, and offer a balance between tasks accomplished and rewards.

- Examples in Cost-Effectiveness Considerations in OPITR

One of OPI's goals was to develop intellectual property of value to industry. Knowledge developed by OPI in Unity House was used by BH to develop a series of four houses offered in today's market under the name of "Unity Collection" (confidential, personal interview, 2009). This collection of prefabricated, cost-effective, environmental friendly houses uses Open-Built systems of design and construction, with the same criteria of sustainability and innovation applied in Unity House. Media coverage was an additional bonus for BH, whose work was featured in the PBS series "This Old House," allowing BH's Open-built system of design and construction to be exposed to a larger audience (confidential, phone interview, 2008). 
Even though BH's participation in OPI was an expensive investment from a financial perspective, it was cost effective if valued from other points of view. It was valuable in terms of TR's experience, knowledge acquisition, and networking (Stokols, et al., 2008). BH had always been interested in developing innovative building and design systems. BH's owner explained that he had come to the realization that "as a single company in the building field he could only go so far" (confidential, personal interview, 2009). Thus, he got involved with MIT and the Open Source Building Alliance, and decided to form a partnership with MIT which became the OPI. In this way BH's could not only use MIT's facilities, reputation, network and links to industry as a way to reach out to the industry as a whole, but also found a space to think creatively about the future of the housing industry (confidential, personal interview, 2009).

Literature review describes several other types of rewards for participation in TR. TR's participants within academic environments receives a type of reward described as "peer recognition" (Stokols, et al., 2008). BH's owner was acknowledged with an honorary degree from Unity College and invited to address the commencement speech (confidential, personal interview, 2009). For BH, CM and Unity College, media coverage was an added value and a form of reward (Stokols, et al., 2008).

CM VP confirmed that "when their organization partnered with OPI they took a chance," and expressed that "their participation in OPI had some value beyond the cost of building a house," making a comment in reference that houses could be built a lot cheaper (confidential, personal interview, 2009). From CM's perspective, media coverage about $\mathrm{O} 1$ meant good advertisement as well as good public relations with the media and community. CM VP expressed "that media's coverage would draw attention to 
their organization which in turn might lead to other things," other projects and collaborations (confidential, personal interview, 2009). In a similar note, the Associate Director of College Communications of Unity College affirmed that the school used O2's coverage as a marketing instrument and educational tool, to draw attention and value to their environmental programs, by using the house as.the flagship for their institution (confidential, phone interview, 2009). Although in financial terms, OPI was not costeffective, all stakeholder participants were satisfied with the results of their participation in $\mathrm{O} 1$ and $\mathrm{O} 2$, and recognized a balanced compensation between tasks accomplished in OPI and rewards received.

\section{The Continuity of Collaboration between Researchers and Practitioners}

A factor mentioned in TR literature review that enhanced OPI's teams' effectiveness is the importance of the continuity of collaboration between researchers and practitioners over extended periods of time and across the various phases of actionresearch, including the formulation of goals and the translation of research into academic and scientific publication, and community empowerment (Stokols, et al., 2008).

- Examples of Continuity of Collaboration between Researchers and Practitioners

The design of the OPI allowed most of teams' participants, researchers and practitioners, to work together in two prototypes. Each prototype took approximately 18 months. BH's owner suggested during the interview that he would be interested in 
accelerating the models, and producing more that the four announced OPI prototypes. As the housing industry and the economy comes out of the recession, he would like to produce a prototype every six months, on a faster schedule, overlapping at a time four different projects on an 18 months schedule, so that OPI would be able to produce prototypes on a regular basis. He was looking forward to engaging more partners and developing more products. In accordance to Stokols' criteria of factors influencing effective TRT's collaboration, BH's owner proposal would enhance teams' success in attaining OPI's goals.

Studies on TR suggest that team's effectiveness is not only influenced by the continuity of members' collaboration over extended periods of time and across the various phases of action-research, but also by the temporal sequence of transdisciplinary collaborative outcomes (Stokols, et al., 2008). In this regard, Open_2 showed a greater level of accomplishment than Open_1. Although it is very difficult to compare both prototypes, $\mathrm{O} 1$ being a home within an organization, designed to accommodate the needs of a changing population of brain injured patients, and $\mathrm{O} 2$ being the home of the president of an environmental college, lesson learned in $\mathrm{O} 1$ were applied to $\mathrm{O} 2$.

MIT's director of architecture declared there was a "dramatic increase" from $\mathrm{O} 1$ to $\mathrm{O} 2$ of the amount of work done in BH's shop and not on the field (confidential, personal interview, 2009). He explained that the goal was to continue in that direction in order to develop "more scalable mass customization concepts, and ultimately into other building types, like multifamily housing" (confidential, personal interview, 2009). On this same topic, an OPI BH systems building team's representative (BH SB) confirmed MIT director's appreciation, stating that "when it came to advancing prefabrication and 
shipping of finished modules, $\mathrm{O} 2$ was a lot further refined than $\mathrm{O} 1$," basically regarding modules completely finished shipped together (confidential, personal interview, 2009). BH SB stated that MIT director was making a reference to "the mechanical bar," a completely finished prefabricated module, which included O2's mechanical room, the kitchen and two bathrooms and that was shipped from the factory setting to the job site in one piece (confidential, personal interview, 2009).

BH SB also explained that energy efficiency and sustainability topics were better addressed in $\mathrm{O} 2$ than $\mathrm{O} 1$ (confidential, personal interview, 2009). In reference to O2's energy efficiency and sustainability, O2's Resident B confirmed that the design "is remarkable in a Net-Zero, sustainable way," and added that "it is a great experience to live in this house," noting that "it is very comfortable" (confidential, phone interview, 2009).

Participants in TR considered OPI as an opportunity for mutual learning and valued the end result as much as the course of action taken. The creation of transformational knowledge was considered critical to the research process, as it allowed the incorporation of lessons learned in $\mathrm{O} 1$ and $\mathrm{O} 2$ into future research initiatives (Wiesmann, et al., 2008). 


\section{DISCUSSION}

\section{Summary of the Study}

This qualitative study identified and analyzed the principal factors and contextual influences that enhanced or constrained effective TR collaboration in accomplishing OPI's goals. This study examined the reasons why OPI is transdisciplinary collaboration and explained the importance of understanding the principles behind transdisciplinary research. The findings of this study used data from OPI principal stakeholders' interviews and from on-site observations. From these findings, several factors influencing OPI's effectiveness were identified. Conclusions based on these findings are presented in this chapter along with recommendations for designing and conducting TR in connection with aging in place research.

\section{Significance of the Study and Conclusions}

An understanding of how contextual circumstances either facilitated or constrained TR effectiveness (Stokols at al., 2008) in achieving OPI's goals, will allow research teams to make educated decisions, and to use lessons learned in $\mathrm{O} 1$ and $\mathrm{O} 2$, to avoid conflicts that affected that collaboration. In addition, these findings may be helpful in developing guidelines for designing, managing, and evaluating successful TR in aging in place.

This study found that TRT effectiveness in OPI was contingent on three principal factors which constrained team success; 1) The ill- defined content and priority ranking of multiple stakeholders' goals, 2) the lack of team organizational structure, and 3) the lack of a designated project leader for $\mathrm{O} 1$ and $\mathrm{O} 2$. Other factors that hindered team effectiveness were 1) uncertainties about sustained support from partners and sponsors to 
the OPI's collaborative efforts and long term goals, 2) lack of funding, and 3) decline of member participation and involvement due to lack of time, initiatives' costs, or absence of strong participatory incentives (Stokols at al., 2008).

Factors identified for enhancing TRT's effectiveness (Stokols at al., 2008) in OPI were 1) participatory identification of common goals, 2) BH's owner transformational leadership style, 3) transformational and empowering style of $\mathrm{O} 1$ and $\mathrm{O} 2$ stakeholder leaders' ability to promote partnerships and teamwork and engage member participation within their organizations, 4) exemplary management skills and leadership traits of $\mathrm{O} 1$ and $\mathrm{O} 2$ project architects, 5) social cohesiveness and familiarity among team members, 6) leaders, stakeholder participants and individual member egalitarian values and mutual respect throughout all stages of collaboration, 7) sustained and continued collaboration among team participants and team leaders, and 8) successful integration of knowledge from different discipline perspectives.

\section{$\underline{\text { Recommendations }}$}

The following recommendations are posed to enhance TR collaboration in OPI in an effort for projects to reach their full potential.

\section{Recommendations to OPI TR}

a) Team Composition

- Interior designer's participation in OPI TR should be instrumental in meeting client's specific goals. 
- Interior designers are trained in issues associated with providing the home with a "soul" and making the home "feel" a certain way, and as such improve residents" quality of life. This consideration should be included in OPI's goals.

- At the moment of joining the TR, new members should be updated on the initiatives' goals and organizational structure.

- OPI members should be selected for their ability to concentrate on finding a subtle balance between respecting specific competences and transgressing them in a productive and critical dialogue (Stokols et al., 2008).

\section{b) Participatory Goal Setting}

- Participatory goal setting should include the discussion of various stakeholders' agendas and expectations.

- Participatory goal setting should enhance collective efficacy by encouraging inclusiveness among team members and helping in the construction of teams with close knit ties and shared beliefs.

- TRT should analyze in depth common goals and outcomes, assessing participant stakeholders' highest-priority ranking of goals and outcomes; these should be revised and redefined as the initiative progresses, considering that the content and relative importance of stakeholders' goals may change and be phase specific. TRT client's selection (prototype's owner) process should be part of a participatory goal setting.

- At the outset of the participatory goal setting process, a TRT clients' profile should be identified. 
- TRT's client is a TRT member. To enhance team efficiency, TRT's client and TRT should share the highest-priority ranking of common goals and outcomes.

- A generalization of $\mathrm{O} 1$ and $\mathrm{O} 2$ design solutions should provide models and approaches that can be transferred and adapted to other contextual settings of aging in place design.

- OPI should rethink and re-define the concepts of "aging in place," "adaptability," "flexibility" and "affordability" in reference to cost and handicapped accessibility.

- Aging in place design should be further implemented by OPI.

- Even though distance considerations of the principal reasons for the absence of pervasive behavioral computing systems research in $\mathrm{O} 1$ and $\mathrm{O} 2$, privacy concerns were directly associated to this topic. Ethical issues including privacy considerations should be addressed at the beginning of the TR.

- One of MIT's goals for $\mathrm{O} 3$ is to introduce an experimental "lab-type" home into the research. TR should include the negotiation of this topic into the participatory goal setting. Among other considerations, this goal defines a client's profile, as the "client" should be willing to live in a lab-type home.

\section{c) Organizational structure}

- A carefully discussed organizational structure, with sequenced and selected participatory interventions and interactions should support project architects and team leaders' decisions, refining problem definition and facilitating problem solving. 
- A communication system should be discussed and implemented in the beginning of the TR. Discussion should include various stakeholders' communication styles, level of involvement and participation.

d) Leadership Solutions

- Select and train a Transformational Leader

- A leader with a transformational style of leadership is recommended for O3. A transformational leader would provide his vision and sense of mission to enhance OPI. He will inspire; build trust and respect among partners. He will be coach and adviser. The transformational approach to leadership focuses on actions of inspiring leaders as they attempt to meet the higher level needs of followers.

Transformational leaders are often creative, masterful communicators, interactive, visionary, empowering, and passionate (Hackman \& Johnson, 1991)

- A designated project leader is necessary to facilitate effective decision making.

- A general project leader per prototype should be responsible for making final decisions.

- A designated leader would effectively keep the prioritized goals of the team in mind when making decisions.

- Trained leaders are able to bridge members' different scientific, technological, and social agendas when making decisions and this can help improve the quality, acceptance and sustainability of OPI's design solutions. 
- OPI's organizational and geographic scope involves multiple locations. If necessary, on-site leadership responsibilities should be shared and coordinated among multiple directors.

- The presence of site-coordinators or project managers is essential to improve efficiency.

e) Funding and Budget

- Sponsors' commitment level should be confirmed at the beginning of the initiative and discussed as an important part of participatory goal setting.

- Funding from different sources should be confirmed at the beginning of the initiative and discussed as an important part of participatory goal setting.

\section{LEED certification versus Universal design}

As populations grow older, they share the common denominator of having some level of disability to accomplish daily activities. People are not disabled by their physical differences, rather are disabled only when they cannot do what they want to do. Aging in place designers, who work with theories of Universal design have the knowledge to design environments that accommodate and "empower" people of all conditions, and all ages. Research in aging in place needs to enhance aging populations' possibilities to do what they want to do. There should not be negotiations on sustainability issues against universal design solutions.

Sustainable research should go beyond ADA requirements by incorporating universal design solutions in every prototype. 
According to LEED certification standards, projects earn points if multidisciplinary teams start working together at early stages of the project. This study recommends that when design solutions are not based on comprehensive universal design principles and carried out throughout the project, LEED certification should discount points. LEED certification and universal design specialists should work together providing specific design solutions on issues where principles from both bodies of knowledge collide.

Aging in place research should be designed as TR collaboration. Within the research, and limiting this comment just to the design field, the bodies of knowledge of all design disciplines should be integrated. From the outset of collaboration, architects with project managing skills, architects with computing research knowledge, designers with cutting edge technology knowledge, industrial designers, and qualified interior designers should be involved.

OPI TRT did not have the significant participation of interior designers. The teams' consensus, guided by MIT's director, was that in a project undertaken holistically there was no boundary between architecture and interior design. Though architects and interior designers share design knowledge; the areas of expertise are different in regards to interior design specialization. This differentiation may be compared to the differences existing between the areas of expertise of a general doctor and a heart doctor. For example, when a person has a heart problem, would it be convenient for this person to seek the help of a general practitioner, a family doctor or a cardiologist? This comparison applies. A significant component in OPI's aging in place research centers on developing innovative interior design solutions. OPI design teams should integrate all design 
knowledge and develop innovative forms of design specialization, with research being driven by the collusion between specialization and transformation of disciplines.

\section{Recommendation to design professional organizations}

As a way to encourage effective TR, professional design organizations, such as ASID and AIA, should go beyond solely promoting traditional multidisciplinary collaborations and support TR. These organizations should develop and promote collaborative networks among a broader range of disciplines, and provide a bridge for transdisciplinary and disciplinary references.

Although there was significant dedication and effort involved in $\mathrm{O} 1$ and $\mathrm{O} 2$, as expressed by BH's owner, research in aging in place is just in its earliest stages. TR is an appropriate form of research to be used when searching for effective, sustainable solutions to improve the quality of aging in place research.

TR' effectiveness was further analyzed using all Stokols' (2008) factors as variables. As a limitation to the present study, the investigator states that only the factors that were critical to TRTs' grade of effectiveness in accomplishing OPI's goals were included in the present analysis. The sum of OPI stakeholders' efforts was more significant than the finished prototype itself, and as such the process provided insight into the factors that affected OPI's accomplishments. These insights provide a significant foundation of transformational knowledge and enhance future initiatives. 


\section{LIST OF REFERENCES}

American Society of Interior Designers (ASID), (2004), Designing for aging in place Toolkit. Retrieved March 2008, from http://www.asid.org/designknowledge/aa/inplace/

American Society of Interior Designers (ASID), (2004), Home for a lifetime. Retrieved March 2008, from http://www.asid.org/designknowledge/aa/inplace/

American Society of Interior Designers (ASID), (2004), Universal Design: New relevancy for the $21^{\text {st }}$ century. Icon magazine.

American Society of Interior Designers (ASID), (March/April, 2009), Putting the "i" in team. Icon magazine.

Barlow, J, Venables, T. Will technological innovation create the true lifetime home? (2004). Innovation Studies Centre, Tanka Business School, Imperial College, London, UK. Housing Studies, 19 (5), 795-810

Center for aging services technologies (CAST), (2006). Imagine-The future of aging: Vision video introductory guide. Retrieved March 2008, from http://www.agingtech.org/index.aspx

Chan, M., Esteve, D., Escriba, C., \& Campo, E. (2008). A review of smart homes-Present state and future challenges. Computer Methods and Programs in Biomedicine, 91, 55-81.

Czaja, S. J., \& Lee, C. C. (2007). The Impact of aging on access to technology. Universal access in the information society, 5 (4), 341-349

Essa, I. A., Georgia Institute of Technology (2000). Ubiquitous sensing for smart and aware environments. IEEE personal communications, October 2000, 1-8. Retrieved March 2008 from http://www.awarehome.gatech.edu/publications/pp.pdf

Habraken, N. John (1972). Supports, an alternative to mass housing, The Architectural Press, London.

Habraken, N. J. (1994). The open building approach: examples and principles. Housing Seminar, Taipei, ROC.

Hart, S. (2002). The house of the future has arrived, Building Science, 190 (7), 149-153.

Helal, S., Mann, W., El-Zabadani, H., King, J., Kaddoura, Y., \& Jansen, E. (2003). The Gator tech smart house: a programmable pervasive space. IEEE Computer Society.

Retrieved March 2008 from

http://www.icta.ufl.edu/projects/publications/helal_GTSH_IEEE Computer March 200 5.pdf 
Intille, S.S. (2002). Designing a home of the future. IEEPE Pervasive Computing Journal, April-June, 80-86. Retrieved March 2008 from http://web.media.mit.edu/ intille/papers-files/PervasiveComputing02.pdf

Intille, S.S, Larson, K., \& Munguia Tapia, E. (2003), Designing and evaluating technology for independent aging in the home, white paper. Changing Places / House_n, Massachusetts Institute of Technology. Retrieved March 2008 from http://web.media.mit.edu/ intille/papers-files/IntilleLarsonTapia03.pdf

Intille, S.S. (2004). A new research challenge: persuasive technology motivates healthy aging. Transactions on information technology in biomedicine, 8 (3), 235-237. Retrieved March 2008 from http://ieeexplore.ieee.org/xpl/freeabs_all.jsp?arnumber=1331399

Intille, S. S., Kent, L., Beaudin, J.S., Nawyn, J., Munguia Tapia, E., \& Kaushik, P., (2005) A living laboratory for the design and evaluation of ubiquitous computing technologies. Cambridge Institute of technology, ACM, 2. Retrieved March 2008 from http://web.media.mit.edu/ intille/papers-files/IntilleLarsonETAL05.pdf

Intille, S.S. (2006). The goal: smart people, not smart homes. House_n, Massachusetts Institute of technology, OIS Press. Retrieved March 2008 from http://web.media.mit.edu/ intille/papers-files/IntilleICOST06.pdf

Knecht, B. (2004). Aging Baby Boomers want smart houses for their golden years; University researchers are developing intelligent environments for aging in place. Architectural Technology Science, 192 (4), 167.

Larson, K. (2003). MIT PlaceLab, a House_n + TIAX Initiative, white paper, Massachusetts Institute of Technology. Retrieved March 2008 from http://architecture.mit.edu/house n/documents/PlaceLab.pdf

Larson, K., Intille, Stephen S., Mc Leish, T., Beaudin, J., \& Williams, R.E. (2004). Open source building, reinventing places of living. BT Technology Journal, 22, 187-200. Retrieved March 2008 from http://web.media.mit.edu/intille/papersfiles/LarsonETAL04.pdf

Leibrock, C. (2008). The secrets of aging beautifully. Retrieved March 2008 from http://www.agingbeautifully.org/harvard.html

Leibrock, C. (2008). Professional development courses. Retrieved March 2008 from http://www.agingbeautifully.org/profdev.html

MIT, (2007). Open source building alliance, white paper. Massachusetts Institute of Technology. Retrieved March 2008 from http://architecture.mit.edu/house n/documents/OSBA $\% 20$ white $\% 20$ paper.pdf

Morris, M., Intille, S.S., \& Beaudin, J. S. (2003). Embedded assessment: overcoming barriers to early detection with pervasive computing, Proactive Health, Intell Research, 
House n, Massachusetts Institute of Technology. Retrieved March 2008 from http://web.media.mit.edu/ intille/papers-files/MorrisIntilleBeaudin05.pdf

Peifer, S. (2008). The state of technology in aging services in California. Center for aging services technologies (CAST). Retrieved March 2008, from http://www.agingtech.org/index.aspx

Pohl, C., \& Hirsch Hadorn, G. (2008). Principles for designing transdisciplinary research; The principles in brief. Swiss Academies of Arts and Sciences, 20-23. Retrieved March 2009, from http://www.transdisciplinarity.ch/documents/knowledgeforms principles.pdf

Pohl, C., von Kerkhoff, L., Hirsch Hadorn, G., \& Bammer G. (2008). Core terms in transdisciplinary research. Handbook of Transdisciplinary Research, 28, 427-432. Retrieved March 2009, http://www.transdisciplinarity.ch/d/Transdisciplinarity/documents/HB Core terms.pdf

Sanders, J.M. (2000). Sensing the subtleties of everyday life, GT Research Horizons, Winter 2000, Retrieved March 2008 from http:/gtresearchnews.gatech.edu/reshor/rhwin00/main.html

Stokols, D., Misra, S., Moser, R. P., Hall, K.L., \& Taylor, B.K., (2008). The ecology of team science. American Journal of Preventive Medicine, 35 (2S), S96-S115.

The Center for Universal Design (1995). Emerging technologies for independent living, report from a working conference; November $21 \& 22,1994$, Baltimore, North Carolina State University, Center for Universal Design Publications, 1-11.

U.S. Department of Health and Human Services, Administration on aging (2007). Profile of older Americans: 2007.

U.S. Department of Health and Human Services, U.S. Department of State, National institute on aging, National Institutes of health (2007). Why population aging matters, a global perspective.

Wiesmann, U., Biber-Klemm, S., Grossenbacher-Mansuy, W., Hirsch Hadorn, G., Hoffmann-Riem, H., Joye, D., Pohl, C., \& Zemp, E. (2008). Enhancing transdisciplinary research: A synthesis in fifteen propositions. Handbook of Transdisciplinary Research, $27,433-441$. 


\section{Appendix A}

\section{Open-Ended Questionnaire}

One of the goals of the Open Prototype Initiative is to use "Open-Built" systems of design and construction to build prototypes. This system suggests that customers become designers at the center of the design process by receiving personalized information about design, products and services, with the purpose of producing a mass customized home, tailored to the client's needs.

1. How would you describe your participation in the multidisciplinary team working in the design and building process of Open_1 and Open_2?

2. How were the members of the multidisciplinary team selected and recruited?

3. Which disciplines were represented in the multidisciplinary teams?

4. Were interior designers invited to participate in the Open_n Prototype Initiative?

Please explain reasons.

5. Please describe the "work mechanics" of the multidisciplinary design team in reference to
a) Number of members
b) Description of members' tasks
c) Number of meetings
d) Place of meetings
e) Other

6. How and by which members of the multidisciplinary team was "Open_1" and "Open_2" interior design project addressed?

a) How did designers analyze client's needs, goals, preferences and requirements?

b) How would you describe the design concept development process?

c) How was the space planning addressed by the design team?

d) How was accessibility design issues addressed by the team? 
e) How was the strategic planning and existing site conditions addressed in the design of the space and the interiors?

f) How were economic factors, influences, and trends, addressed by the multidisciplinary team?

- environmental factors

- sustainability

- indoor air quality

- energy conservation issues

- innovations

g) How was the project context, location, surroundings, view and geography addressed by the design team?

h) How were the interior design components and detailing addressed by the design teams?

i) How was cabinetry, furnishings, materials, fixtures, lighting fixtures, lamps etc., proposed, selected, and specified by the design team?

j) How were the psychological factors, including issues of psychology of color addressed by the design team?

7. How was the design communicated by the design team? Considering the following list, which of these elements did the graphic presentation of the project include?

a) Elements incorporated from the 3D "Open-Built" System catalogues

b) $3 \mathrm{D}$ modeling?

c) Custom designs?

d) Sketches?

e) Drawings?

f) Construction documents?

8. Have you participated of the multidisciplinary team's meetings at any/some/ all stages of the design and construction process?

9. How would you describe the management of the project from the "House_n Research Group" and "Open_n Prototype Initiative's Director's " point of view, regarding issues of cost, design and construction time (on-site and off-site), and quality? 
10. Which design features make "Open_1" and "Open_2" be adaptable to occupants/ residents' changing needs? Do these features perform to your expectancies?

11. Which ubiquitous and pervasive computing systems related to home-based health and/or energy management are embedded into the project?

12. According to the Open Prototype Initiative's goals, the Open n prototypes are designed as "new ways of creating places of living". Would you like to comment on any design features, products and systems related to design, fabrication, construction and use that makes remarkable in that sense?

13. What market-ready products were used in "Open_1" and "Open_2" to increase the efficiency, quality, and cost-effectiveness of the house?

14. How would you describe the performance of "Open_1", and "Open_2" related to
a) thermal efficiency
b) maintenance
c) air quality
d) noise and privacy
e) dimensional constraints
f) comfort
g) patients' independence

15. How would you evaluate the advances in the Open_n Prototype's research in connection with aging in place design?

16. How would you describe the lessons learned, after Open_1 and Open_2? 


\section{Appendix B}

\section{CONSENT TO PARTICIPATE IN A RESEARCH STUDY}

\section{Title:}

\section{$21^{\text {st }}$ Century Homebuilding Housing:}

\section{The Interior Designers' Role in Aging in Place Design}

You are being asked to participate in an interview as part of a research study conducted by Liliana Custy. She is a graduate student at FIU investigating multidisciplinary teams working on open building systems. The project involves two case studies: the Open_1 Mountain Crotched Rehabilitation Center and the Open_2 Unity House. The study is going to entail on-site observations and semi-structured interviews with the stakeholders involved in the Open Prototype Initiative and the Open_1 and Open_2 Prototypes. We are exploring the contribution different stakeholders have on the multidisciplinary teams developing $21^{\text {st }}$ century homebuilding prototypes.

The investigator is planning to visit the Open_1 and Open_2 Prototypes, Bensonwood Homes and MIT School of Architecture. Prior to the visit we will communicate with you to schedule a meeting for the interview. If you choose to participate, the interview should take approximately one hour of your time. During the interview, you will be asked to answer general questions about: 1) your participation in the Open Prototype Initiative 2) characteristics of the project 3 ) jobs that you have had during the design and construction of the prototypes; 4) what do you think about the experience, 5) how do you evaluate the results; and 6) what were the lessons learned.

We do not expect to have any harm come to you by participating in the study. You may skip any questions that you do not want to answer. If you get upset or feel uncomfortable during the interview, you may ask to take a break, or you may also choose to terminate the interview at any time. You may ask questions about the study whenever you like. If you choose not to participate, no one will be upset with you, and your lack of participation will not be discussed with anyone outside the research team.

Unless you give us written authorization to mention your name, your name will not be disclosed in any public documents. Your interview will be identified by a random number not by your name. All of your answers are private and will not be shared with anyone unless required by law. Your data will be compared to the data of the other subjects. We will present the research results as a group.

There is no cost or payment to you as a subject. You will not get any direct benefit from being in the study. However, your help will give us information about how multidisciplinary teams successfully operate when working in the advancement of the building industries. 
If you would like more information about this research after you are done, you can contact Ms. Janine King or me at 305-348-6630. If you feel that you were mistreated or would like to talk with someone about your rights as a volunteer in this research study you may contact Dr. Patricia Price, the Chairperson of the FIU Institutional Review Board at 305-348-2618 or 305-348-2494.

Your signature below indicates that all questions have been answered to your liking. You are aware of your rights and you would like to be in the study.

Signature of Participant Printed Name

Date

I have explained the research procedure, subject rights and answered questions asked by the participant. I have offered him/her a copy of this informed consent form.

Signature of Witness

Date 


\section{Table 1: RELATIONSHIP BETWEEN INTERIOR DESIGNERS' BODY OF KNOWLEDGE AND OPI'S GOALS}

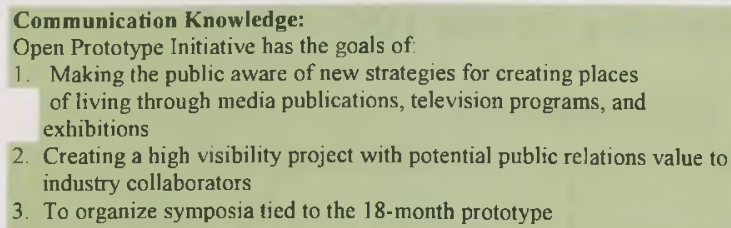

Open Prototype Initiative has the goals of

1. Making the public aware of new strategies for creating places of living through media publications, television programs, and exhibitions

2. Creating a high visibility project with potential public relations value to industry collaborators

3. To organize symposia tied to the 18 -month prototype

\section{Design Knowledge:}

Open Prototype Initiative has the goals of:

1. Creating a new paradigm developing a better design \& building system for homes in America

2. Mass-customization: home should be unique $\&$ adaptable

3. Planning inclusively \& building virtually

4. Component library with pre-designed parts of the home, providing custom options

5. Design for flexibility: systems \& components are designed to accommodate to changing needs and uses

6. Multidisciplinary teams meet in the factory and work in interdisciplinary design decisions at every stage of the project 7. Clients work with teams in
Furnishings, Products \& Materials Knowledge:

Open Source Building Alliance \& Open Prototype Initiative have

the goals of:

1. Adaptability: designs change with technology, occupancy and use Walls can be removed or repositioned with simple hand tools (interior walls and fit out systems)

2. Create research into new systems $\&$ products related to fabrication, construction \& use.

3. Conduct research into emerging next generation consumer design, configuration and visualization tools

4. Engage industry partners to create market-ready products \& prototype of future products to increase efficiency, quality $\&$ costeffectiveness of housing
BODY OF KNOWLEDGE CATECORTS
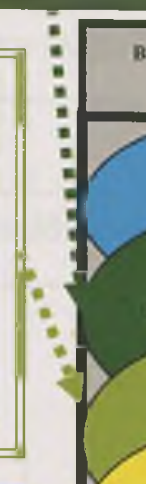
Table 2: HOUSE_n RESEARCH CONSORTIUM

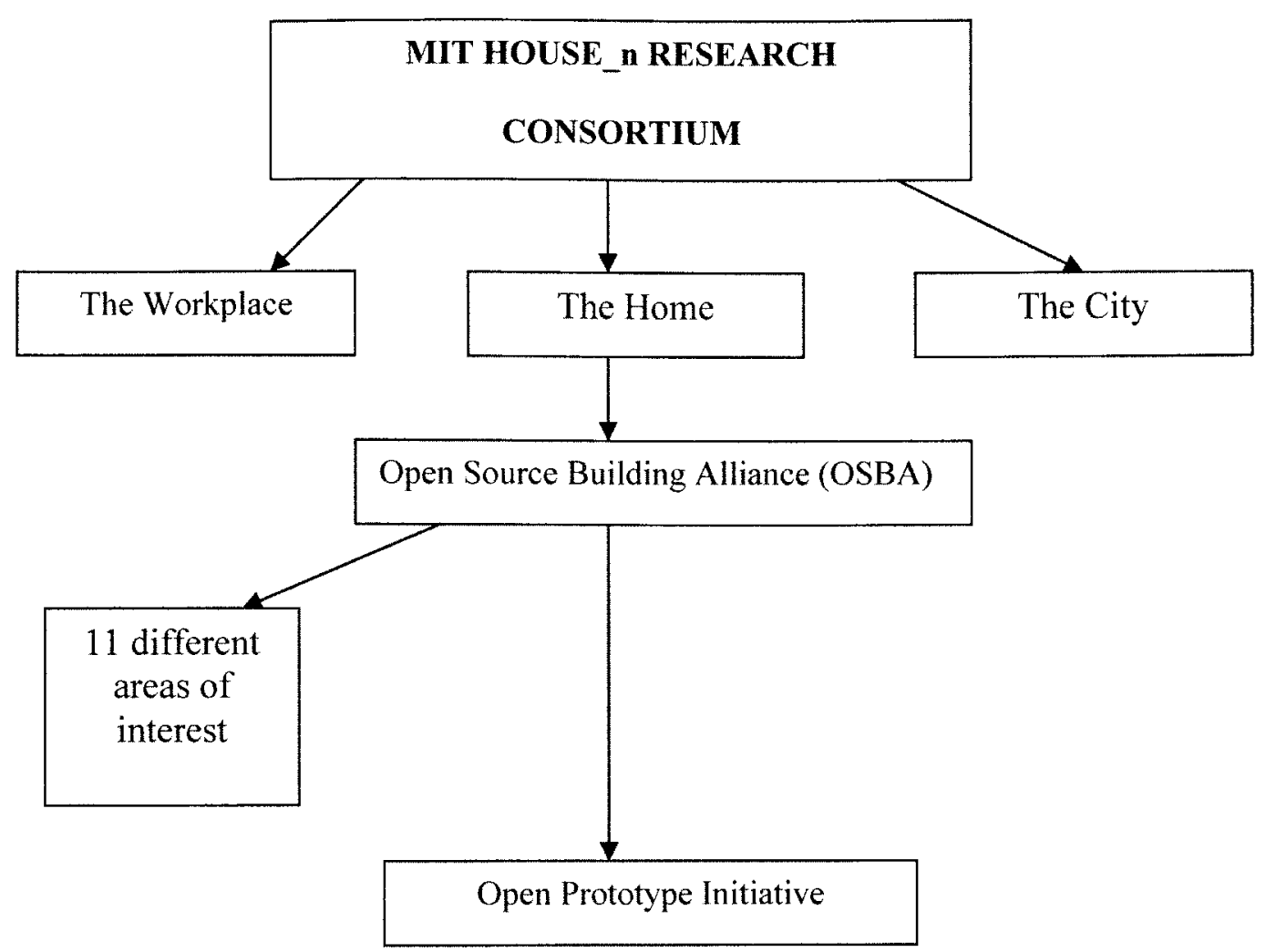


Table 3: OPEN PROTOTYPE INITIATIVE (OPI)

\section{OVERARCHING GOALS}

\section{OPI OVERARCHING GOALS}

- To bring the public a better design and building process

- Better management of home construction

- Less risk for buyer and builder

- Increased certainty of cost, time and quality for buyer

- Increased efficiency for builder

- Share the innovations with the construction industry to help builders create higher quality and more environmentally friendly and energy efficient homes 


\section{Table 4: OPEN PROTOTYPE INITIATIVE (OPI)}

\section{GOALS}

\section{OPI GOALS}

(retrieved from www. Openprototype.com)

1. To conduct research into new systems and products related to design, fabrication, construction, and use

2. To conduct research into emerging next-generation consumer design, configuration, and visualization tools

3. To actively engage industry projects that create both market-ready products and prototypes of future products that would increase the efficiency, quality, and costeffectiveness of housing

4. To deploy new networks, sensors, and application related to home-based health, energy management, as they become available for implementation

5. To evaluate proposal and product viability with respect to business models, buildability, marketability, cost-effectiveness, performance, etc.

6. To define design and performance standards for building systems related to thermal efficiency, hurricane resistance, mold prevention, life spans of systems, maintenance, air quality, noise, dimensional constraints, comfort, etc.

7. To make public aware of new ways of creating places of living through such media as publications, television, and exhibitions

8. To develop intellectual property of value to industry

9. To organize symposia tied to the 18-months schedule, and host special topic workshops

10. To secure funding for this effort from corporate sponsors and governmental agencies 


\section{Table 5: OPEN PROTOTYPE INITIATIVE (OPI)}

\section{DESIGN ELEMENTS}

\section{OPI DESIGN ELEMENTS}

\section{Design elements are construction elements}

- In addition to the cataloging of elements such as stairs windows and doors, the Open Prototype Initiative has the goals to demonstrate that design using 3D modeling coupled with the use of high speed precision cutting machinery not commonly used in today's home construction, reduces waste, and speeds construction by enabling large sections of the home to be installed aided by cranes, leading to higher quality home built in a short period of time (retrieved from www.openprototype.com)

- The Open Prototype Initiative demonstrates that bringing contractors and subcontractors to the table before on-site construction begins, allows for greater coordination of the project allowing for extensive pre-planning with all the skilled labor involved in the project.

- The "Build-it" meeting reduces the likelihood of conflicting ideas ands goals on-site that result in construction delays as well as inefficient installation and layout of electrical, plumbing and HVAC and other services.

- The purpose of this study is to explore how interior designer's body of knowledge would contribute to basic topics of design, such as:
a) cataloging of design elements for Open-Built Systems
b) multidisciplinary meetings
c) analyzing clients' needs
d) conceptual development
e) proposal of infill solutions for existing homes 
Table 6: OPEN_1 CROTCHED MOUNTAIN REHABILITATION CENTER

GOALS

\section{OPEN_1 GOALS}

(retrieved from www.openprototype.com)

- Design and construction will establish a varied collection of components that can be combined to form unique structures, linked directly to efficient prefabrication

- The structure and components will incorporate "Green" and energy efficient designs

- The floor, wall and roof systems will be pre-built

- The structure will consist of distinct, disentangled and accessible layers that allow for both efficient assembly and for change overtime

- The building shell, with exterior finish, will be assembled in five working days

- Mechanical, electrical, and plumbing systems, will be installed in three working days

- Interior fit-out will be completed in five working days

- Interior finishes will be completed in five working days

- To host a symposium to evaluate Open_1, and to set the goals for Open_2

- Additional goals may be established through the involvement of industrial sponsors

- Subsequent prototypes will be incrementally more ambitious, with specific goals established by the academic and industrial participants, including technology developed through the MIT House_n Initiative. 
Table 7: OPEN_1 CROTCHED MOUNTAIN REHABILITATION CENTER

KEY FEATURES

\section{OPEN_1 KEY FEATURES}

(retrieved from www.openprototype.com)

- Design and construction will establish a varied collection of components that can be combined to form unique structure and allow walls to be moved so the layout of the home meets changing needs.

- Efficient prefabrication allows for adaptability over time, allowing home owners to add services or seamlessly expand the house faster and with minimal mess and waste.

- On-site construction waste will fill only two trash cans.

- "MITes" (MIT environmental sensors), a system of sensors and algorithms will be installed throughout the home to support occupants and monitor, and analyze the performance of the home and its environment to help optimize the building's performance.

- The structure and components will incorporate "Green" and energy efficient designs as well as systems to monitor and measure air quality, heat, and energy efficiency.

- The floor, wall and roof systems will be pre-built with wiring pre-installed.

- The structure will consist of distinct, disentangles and accessible layers that allow for both efficient assembly and for change overtime

- Floors, ceilings and baseboards will allow for easy access to plumbing, heating and wiring.

- 'Stacked' design closets makes a shaft to allow for easy installation of an elevator to aid universal design and "aging in place" needs (Open_l will incorporate an elevator to meet the needs of Crotched Mountain Brain Injury Clinic clients) 
Table 8: OPEN_2 UNITY HOUSE'S GOALS

\section{OPEN_2 UNITY HOUSE GOALS}

(retrieved from www.openprototvpe.com/proiects/open2/open2index.html)

- Build a Net-zero energy home. The design and construction will take advantage of state-of-the-art technology and systems, to produce a home that is energy efficient, highly insulated, and produces as much energy as it uses.

- Using architecture and detail, express a new model for design, fabrication, and assembly. This model could establish a system for a series of affordable, high performance, low energy houses

- Deploy state-of-the-art passive solar design and energy producing systems, as well as develop energy-efficient systems and components using sustainable materials.

- Incorporate a single, prefabricated assembly containing all utility-intensive spaces and systems. This module will contain the kitchen, the bathrooms, utility rooms, water supply/processing, heating and cooling equipment, and other utilities.

- Engineer interior wall and fit out systems that with a few simple operations, allow the transformation of spaces so that a relatively small house can function as a large house. For example, the guest room converting to a media room or to an expanded dining room.

- Use Open-Built prefabricated components to construct the house from the foundation up in under 20 days. 


\section{Table 9: OPEN_2 UNITY HOUSE'S DESIGN CONCEPTS}

\section{OPEN_2 UNITY HOUSE'S DESIGN CONCEPTS}

(Retrieved from www.openprototype.com)

- Reflect Unity's commitment to environmental issues: The house will reflect the college's environmental commitments and their rural, New England nature and in touch with the local climate

- Encourage pedestrian connection to town and campus: The president's house will be located on the north side of the campus. It is important that this house has a presence, but is not central to campus activity. The chosen location allows for a visual connection both to the campus above and cars arriving in either direction

- Connection to the outdoors: The president of Unity College desired that 'The house should be designed so that a person knows where they are'. The building is an integral part of the landscape rather than an object in it. Materials and spaces will be designed with 'biophilic' features, reminding people of the natural world around them

- Architecture as pedagogy: Opportunities for experiential learning are integrated into the design. As a laboratory for learning about environmental issues, the building will create opportunities to enrich the curriculum.

- Structurally honest: Celebration of structural elements will help to facilitate learning and connect people to local resources. Structural elements will include the use of local woods to New England.

- Powered by renewable energy: Design to meet the goals of Net-Zero energy and Carbon Neutral initiatives as defined in the Living Building Challenge. On-site renewable energy generation will also provide ample opportunity for experiential curriculum.

- Environmentally responsible water use: The building will use water in a frugal and environmental responsible manner, using grey water and water recovered from precipitation. On-site wastewater treatment is a goal, but may fall under the jurisdiction of Unity's master planning which is beyond the scope of this building

- Maintain a high level of indoor environmental quality: Sources of indoor air pollution will be eliminated by incorporating the appropriate amount of air exchanges as defined by California Title 24 requirements and by not permitting toxic, high VOC materials into the space

- Minimize construction waste: Designing with increments of standardized construction practice, modeling this structure in its entirety and prefabricating it in a controlled environment will lend itself to the optimal use of materials, minimizing construction waste to the highest degree possible. 
Table 10: OPEN_2 UNITY HOUSE'S PROJECT PROGRAMMING

\section{OPEN_2 UNITY HOUSE'S PROJECT PROGRAMMING}

- Space: the original patrons of this house will be two adults with no children, both of whom need and office space to work. This couple is very accustomed to living in a limited amount of space, possibly allowing for the original configuration of the house to have more space dedicated to the public realm that the private.

- Public: Function/Multi-purpose common room:

- Living space

- Dining for 20 people

- Seminars and board meetings

- Kitchen - open to Common Room - catered access

- Powder Bath

- Screened Porch

- Mudroom / Storage

- Entry / Foyer

- Private:

- Master Bedroom Suite w/bath

- Guest Bedroom Suite w/3/4 bath (could be a private office?)

- Sitting Space (could be a private office?)

- 2 offices (could convert to bedrooms) 
Table: 11: OPEN-ENDED INTERVIEWS AND ON-SITE INTERVIEWS

Open Prototype Initiative (OPI) \&

House_n Research Group Department of Architecture Massachusetts Institute of Technology (MIT)

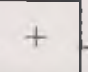

Bensonwood Homes (BH)
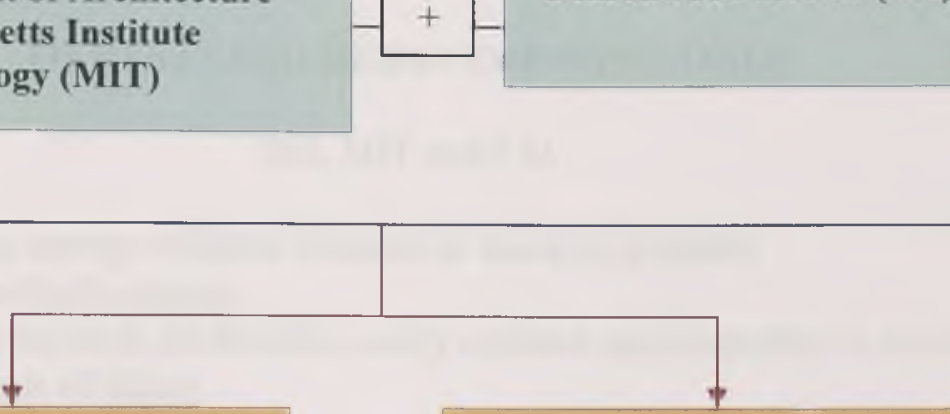

Open_1 (O1)

Crotched Mountain

Rehabilitation Center,

Greenfield, NH

Open_2 (O2)

Unity House,

Campus of Unity College,

Unity, Maine

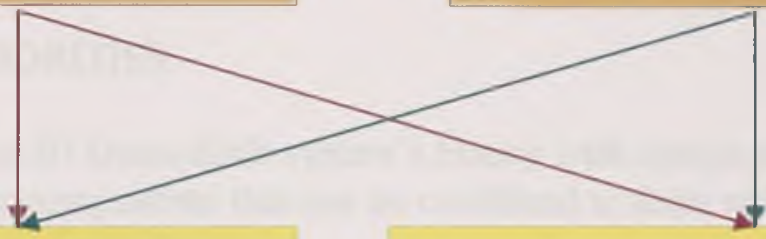

Observation Criteria

Interviews

- Overarching Goals

- Goals

- Key Features

- Design Elements

- Lessons Learned

1. Director of the MIT House_n Research Consortium

2. Project Architects $\mathrm{O} 1$ and $\mathrm{O} 2$

3. Designers $\mathrm{O} 1$ and $\mathrm{O} 2$

4. Builder $\mathrm{O} 1$ and $\mathrm{O} 2$

5. Project Facilitators, Project Managers, other designers and multidisciplinary team members, Bensonwood Homes $\mathrm{O} 1$ and $\mathrm{O} 2$

6. Development Partners $\mathrm{O} 1$ and $\mathrm{O} 2$

7. Product Sponsors $\mathrm{O} 1$ and $\mathrm{O} 2$

8. Director Ol

9. Therapists, patients, and patients' families at $\mathrm{O} 1$

10. $\mathrm{O} 2$ residents

11. O2 Faculty and board members 
Table 12

\title{
O1 STAKEHOLDERS COMMON OUTCOMES
}

\author{
$\mathrm{BH}, \mathrm{MIT}$ and $\mathrm{CM}$
}

- To Design and build a house for brain injured patients transitioning for a hospital setting to a house setting.

\section{O1 STAKEHOLDERS COMMON GOALS}

\author{
BH, MIT and CM
}

1. To use green, energy efficient features as much as possible

2. To use Open-Built systems

3. To allow the house to be flexible, easily updated and adaptable to residents' changing needs of aging

4. To design and built $\mathrm{Ol}$ within a very tight timeline

\section{O1 STAKEHOLDERS' HIGHEST-PRIORITY GOALS}

\section{BH’ HIGHEST-PRIORITIES}

1. To develop a 3D Open-Built system's library with design and construction details to be used as components that can be combined to form unique structures linked to cost-effective prefabrication.

2. To allow the house to be adaptable, flexible and easily updated.

\section{MIT' HIGHEST-PRIORITIES}

1. To develop innovative design components that would provide adaptability to a home setting, making the environment responsive to occupants' changing needs

2. To integrate pervasive computing systems as an as additional technological support to monitor changes in residents' behavior and/or changes in the environment.

\section{CM' HIGHEST-PRIORITIES}

1. To develop a prototype house to provide accessible and affordable housing to brain injured patients. 
2. Two opposite agendas were considered,

a) The house should have a house-like feel

b) The house should have hospital-like features

3. O1's design should

a) integrate aesthetically with the other CM campus buildings,

b) allow for future replication

c) be based upon universal design features

d) be adaptable, flexible and easily updated. 


\section{Table 13}

\section{O2 STAKEHOLDERS COMMON OUTCOMES}

BH, MIT and UNITY COLLEGE

- To design and build a house to accommodate Unity College's presidents and their families.

\section{O2 STAKEHOLDERS COMMON GOALS}

BH, MIT and UNITY COLLEGE

1. To use green, energy efficient features

2. To use Open-Built systems

3. To allow the house to be flexible, easily updated and adaptable to residents' changing needs

4. To design and built $\mathrm{O} 2$ within a very tight timeline

\section{O2 STAKEHOLDERS' HIGHEST-PRIORITY GOALS}

\section{BH' HIGHEST-PRIORITIES}

\section{Project Architect 1}

1. Net-Zero carbon foot print and LEED Platinum certification

2. To allow the house to be updated, flexible and easily adaptable to residents' changing needs

3. To use design solutions based on universal design principles

Project Architect 2

1. To develop a market-ready, cost-effective, net-zero, prefabricated prototype house

2. To develop a 3D Open-Built system's library with design and construction details and components that can be combined to form unique structures linked to costeffective prefabrication.

\section{MIT' HIGHEST-PRIORITIES}

1. To develop innovative design components that would provide adaptability to a home setting, making the environment responsive to occupants' changing needs 
2. To integrate pervasive computing systems as an as additional technological support to monitor changes in residents' behavior and/or changes in the environment.

3. To design a contemporary house with cutting-edge design features

\section{UNITY COLLEGE'S HIGHEST-PRIORITIES}

1. Net-Zero carbon foot print and LEED platinum certification. Sustainable features must be exposed as part of Unity College' educational venue.

2. Internal monitoring systems measure the energy efficiency of the house.

3. Design features allow the house to be adaptable, flexible and easily updated 
Table 14: Factors that Contribute to Team Effectiveness (Perspectives)

\begin{tabular}{|c|c|c|c|c|c|c|c|c|}
\hline \multirow[b]{2}{*}{ OPI } & \multicolumn{8}{|c|}{ FACTORS THAT CONTRIBUTE TO TEAM EFFECTIVENESS IN OPI } \\
\hline & $\begin{array}{l}\text { Designated } \\
\text { Project } \\
\text { Leader }\end{array}$ & $\begin{array}{c}\text { Other } \\
\text { Leadership } \\
\text { Issues }\end{array}$ & \begin{tabular}{|c|} 
Participatory \\
Goal Setting \& \\
Communication \\
Patterns
\end{tabular} & $\begin{array}{c}\text { Identification } \\
\text { of common } \\
\text { goals } \\
\& \text { outcomes }\end{array}$ & $\begin{array}{c}\text { Priority } \\
\text { Rating } \\
\text { of common } \\
\text { goals } \\
\& \text { outcomes } \\
\end{array}$ & $\begin{array}{c}\text { Members' } \\
\text { characteristics } \\
\text { (including } \\
\text { clients) }\end{array}$ & $\begin{array}{c}\text { Organizational } \\
\text { Factors }\end{array}$ & $\begin{array}{l}\text { Funding- } \\
\text { Sponsors } \\
\text { \& partners } \\
\text { Collaboration }\end{array}$ \\
\hline \multicolumn{9}{|c|}{ FROM THE INVESTIGATOR'S PERSPECTIVE } \\
\hline OPEN 1 & WEAK & STRONG & MODERATE & MODERATE & WEAK & STRONG & MODERATE & STRONG \\
\hline OPEN_ 2 & WEAK & STRONG & MODERATE & MODERATE & WEAK & STRONG & MODERATE & WEAK \\
\hline \multicolumn{9}{|c|}{ FROM THE POINT OF VIEW OF BH } \\
\hline OPEN_1 & MODERATE & STRONG & MODERATE & MODERATE & MODERATE & MODERATE & MODERATE & STRONG \\
\hline OPEN_2 & MODERATE & STRONG & STRONG & MODERATE & MODERATE & STRONG & MODERATE & WEAK \\
\hline \multicolumn{9}{|c|}{ FROM THE POINT OF VIEW OF MIT } \\
\hline OPEN_1 & MODERATE & STRONG & MODERATE & MODERATE & MODERATE & MODERATE & MODERATE & STRONG \\
\hline OPEN_2 & MODERATE & STRONG & MODERATE & MODERATE & MODERATE & MODERATE & MODERATE & WEAK \\
\hline \multicolumn{9}{|c|}{ FROM THE POINT OF VIEW OF O1 CLIENTS } \\
\hline OPEN_1 & MODERATE & STRONG & MODERATE & MODERATE & MODERATE & MODERATE & STRONG & STRONG \\
\hline \multicolumn{9}{|c|}{ FROM THE POINT OF VIEW OF O2 CLIENTS } \\
\hline OPEN 2 & MODERATE & STRONG & STRONG & STRONG & STRONG & MODERATE & MODERATE & WEAK \\
\hline
\end{tabular}

References:

Other leadership factors include:

a) the presence of transformational leaders who are very well respected in stakeholders organizations and among coalitions' members, and b) $\mathrm{O} 1 \& \mathrm{O} 2 \mathrm{BH}$ 's project architects transformational leadership style

Members' characteristics include: a) team members' familiarity and social cohesiveness, b) members' readiness

Communication patterns include: a) communication among same team members, b) communication with external team members

Organizational factors include: a) presence of a structure for decision making and b) problem solving 
Table 15: Factors that Contribute to Team Effectiveness (Percentages)

\begin{tabular}{|c|c|c|c|c|c|c|c|c|}
\hline \multirow[b]{2}{*}{ OPI } & \multicolumn{8}{|c|}{ FACTORS THAT CONTRIBUTE TO TEAM EFFECTIVENESS IN OPI } \\
\hline & $\begin{array}{c}\text { Designated } \\
\text { Project } \\
\text { Leader }\end{array}$ & $\begin{array}{c}\text { Other } \\
\text { Leadership } \\
\text { Issues }\end{array}$ & $\begin{array}{c}\text { Participatory } \\
\text { Goal Setting } \\
\& \\
\text { Communication } \\
\text { Patterns } \\
\end{array}$ & $\begin{array}{l}\text { Identification } \\
\text { of } \\
\text { common } \\
\text { Goals } \\
\text { \& outcomes } \\
\end{array}$ & $\begin{array}{c}\text { Priority Rating } \\
\text { of common } \\
\text { goals } \\
\text { \& outcomes }\end{array}$ & $\begin{array}{c}\text { Members' } \\
\text { characteristics } \\
\text { (including } \\
\text { clients) }\end{array}$ & $\begin{array}{l}\text { Organizational } \\
\text { Factors }\end{array}$ & \begin{tabular}{|c} 
Funding- \\
Sponsors \\
$\&$ \\
partners \\
Collaboration \\
\end{tabular} \\
\hline OPEN_1 & \begin{tabular}{|l|} 
STRONG: $0 \%$ \\
MODERATE: $75 \%$ \\
WEAK: $25 \%$
\end{tabular} & $\begin{array}{l}\text { STRONG: } 100 \% \\
\text { MODERATE: } 0 \% \\
\text { WEAK: } 0 \%\end{array}$ & $\begin{array}{l}\text { STRONG: } 0 \% \\
\text { MODERATE: } 100 \% \\
\text { WEAK: } 0 \%\end{array}$ & $\begin{array}{l}\text { STRONG: } 0 \% \\
\text { MODERATE: } 100 \% \\
\text { WEAK: } 0 \%\end{array}$ & $\begin{array}{l}\text { STRONG: } \mathbf{7 5} \% \\
\text { MODERATE: } 0 \% \\
\text { WEAK: } \mathbf{2 5} \%\end{array}$ & $\begin{array}{l}\text { STRONG: } 25 \% \\
\text { MODERATE: } \mathbf{7 5} \% \\
\text { WEAK: } 0 \%\end{array}$ & $\begin{array}{l}\text { STRONG: } \mathbf{2 5} \% \\
\text { MODERATE: } \mathbf{7 5} \% \\
\text { WEAK: } 0 \%\end{array}$ & $\begin{array}{l}\text { STRONG: } 100 \% \\
\text { MODERATE: } 0 \% \\
\text { WEAK: } 0 \%\end{array}$ \\
\hline OPEN_2 & \begin{tabular}{|l|} 
STRONG: $0 \%$ \\
MODERATE: $\mathbf{7 5} \%$ \\
WEAK: $25 \%$
\end{tabular} & $\begin{array}{l}\text { STRONG: } 100 \% \\
\text { MODERATE: } 0 \% \\
\text { WEAK: } 0 \%\end{array}$ & $\begin{array}{l}\text { STRONG: } \mathbf{5 0} \% \\
\text { MODERATE: } 50 \% \\
\text { WEAK } 0 \%\end{array}$ & $\begin{array}{l}\text { STRONG: } \mathbf{2 5} \% \\
\text { MODERATE: } \mathbf{7 5 \%} \\
\text { WEAK: } 0 \%\end{array}$ & $\begin{array}{l}\text { STRONG: } \mathbf{2 5} \% \\
\text { MODERATE: } \mathbf{5 0} \% \\
\text { WEAK: } \mathbf{2 5} \%\end{array}$ & $\begin{array}{l}\text { STRONG: } 50 \% \\
\text { MODERATE: } 50 \% \\
\text { WEAK: } 0 \%\end{array}$ & $\begin{array}{l}\text { STRONG: } 0 \% \\
\text { MODERATE: } 100 \% \\
\text { WEAK: } 0 \%\end{array}$ & $\begin{array}{l}\text { STRONG: } 0 \% \\
\text { MODERATE: } 0 \% \\
\text { WEAK: } 100 \%\end{array}$ \\
\hline
\end{tabular}




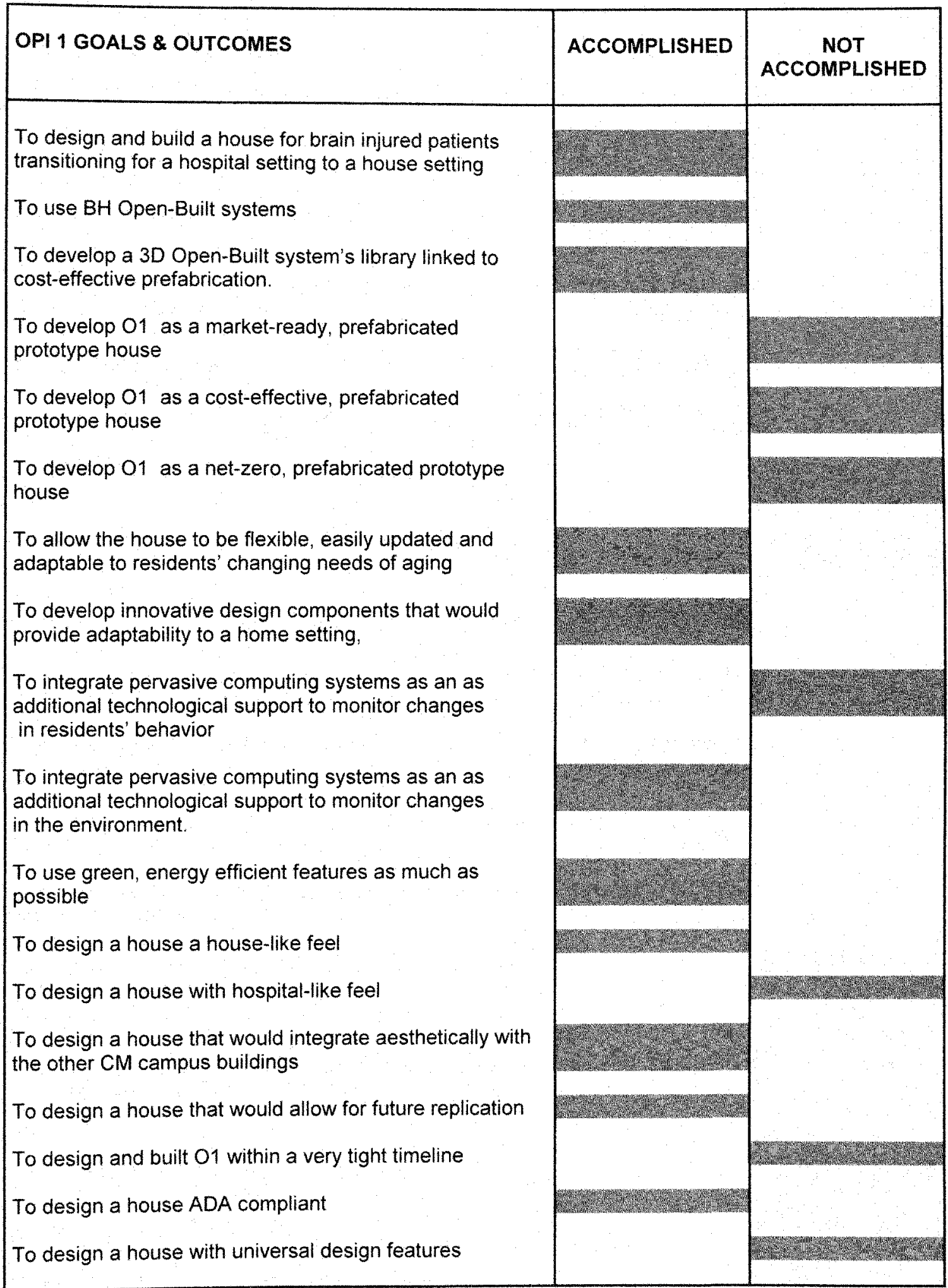


Table 17: $\mathrm{O} 2$ accomplished Goals and Outcomes

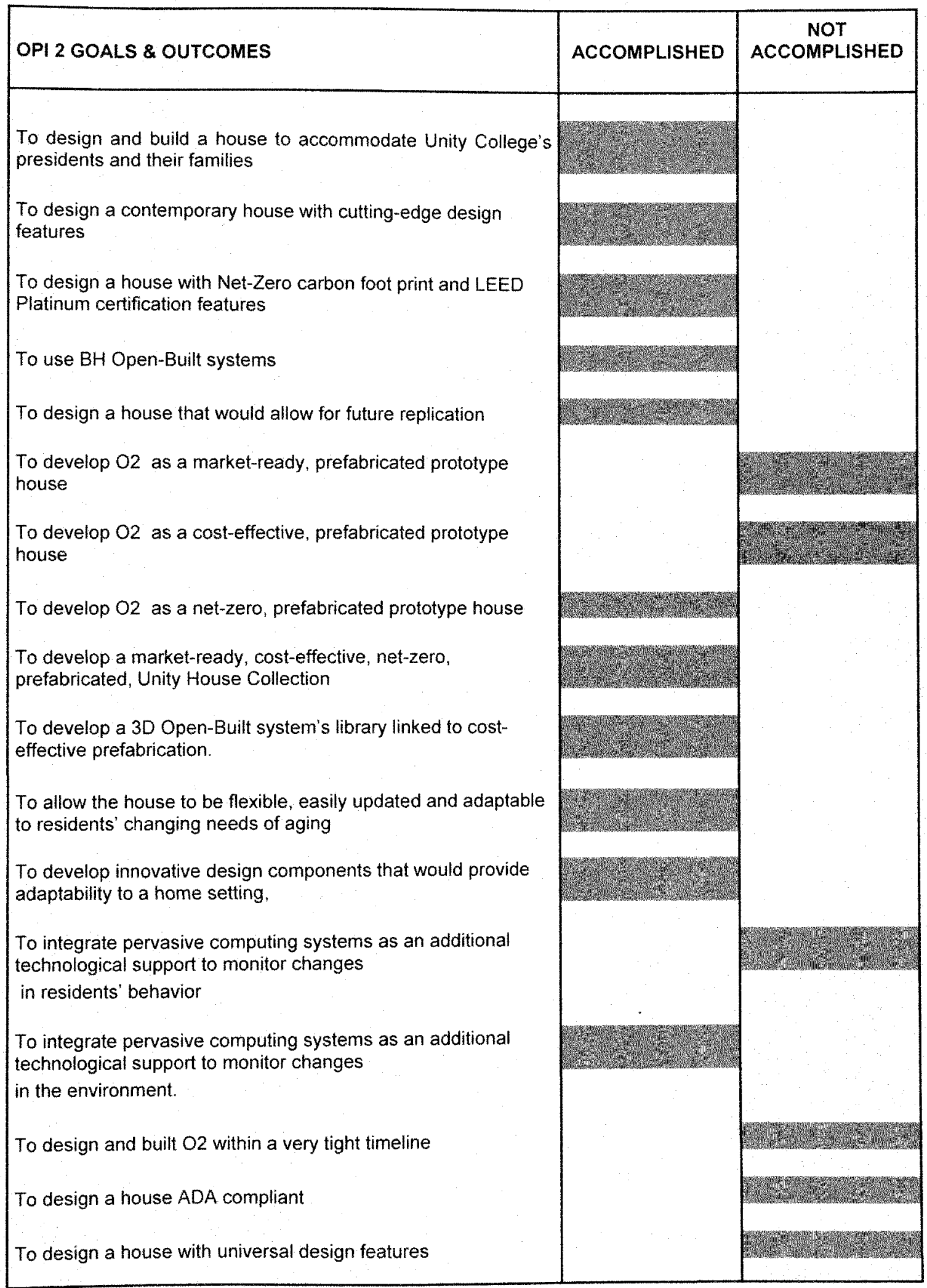

